Customização de interfaces web para clientes de software como serviço multitenant

\author{
Alexandre Michetti Manduca
}





\title{
Customização de interfaces web para clientes de software como serviço multitenant
}

\author{
Alexandre Michetti Manduca \\ Orientadora: Profa. Dra. Maria da Graça Campos Pimentel \\ Dissertação apresentada ao Instituto de Ciências \\ Matemáticas e de Computação - ICMC-USP, como \\ parte dos requisitos para obtenção do título de Mestre \\ em Ciências - Ciências de Computação e Matemática \\ Computacional. VERSÃO REVISADA
}


Ficha catalográfica elaborada pela Biblioteca Prof. Achille Bassi e Seção Técnica de Informática, ICMC/USP, com os dados fornecidos pelo(a) autor(a)

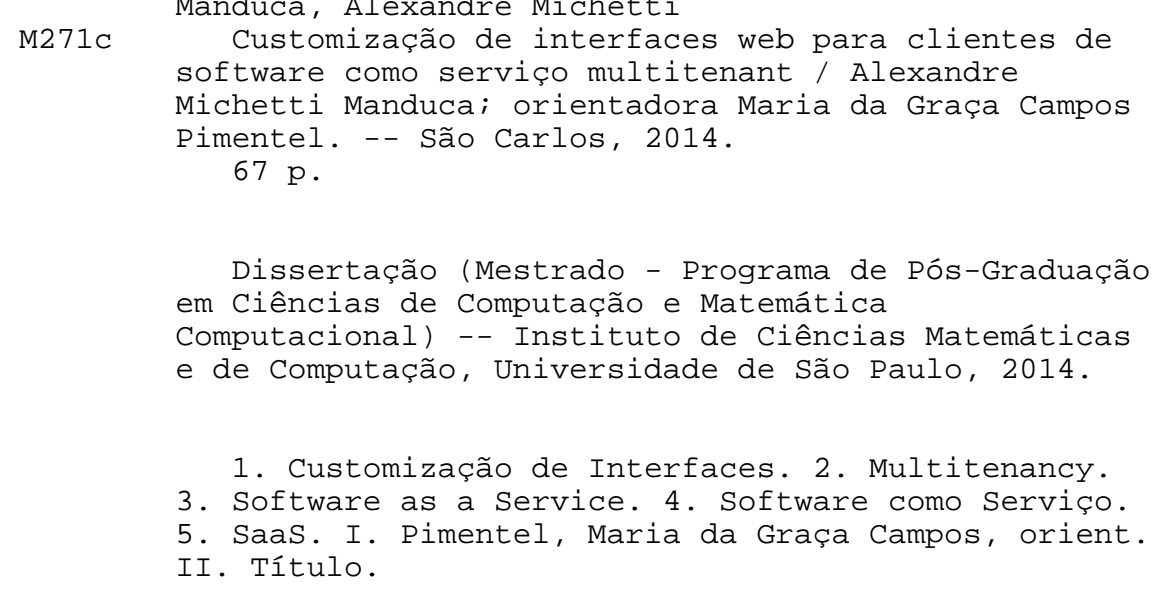


Dedico o resultado deste trabalho a minha esposa Juliana Müzel e nossa filha Giovana Müzel Michetti, por todo amor e por nunca me deixarem desistir. 



\section{Agradecimentos}

Agradeço a todo o tempo dedicado pela Profa. Dra. Maria da Graça Campos Pimentel a conclusão deste trabalho. 

O único lugar onde sucesso vem antes do trabalho é no dicionário.

Albert Einstein 

A adoção de Software como Serviço (do inglês, Software as a Service ou simplesmente SaaS) está em expansão em todo o mundo, alavancada pelas muitas vantagens que esse modelo de distribuição de software oferece tanto para os provedores desses serviços quanto para seus clientes. Em SaaS, o provedor do serviço também é responsável pelo seu desenvolvimento e execução, o que permite a esses provedores fazerem escolhas sobre a arquitetura de seus sistemas visando diminuir a complexidade e os custos relacionados ao seu desenvolvimento e operação. Nesse contexto, um padrão de arquitetura freqüentemente utilizado é o Multitenant, que torna uma mesma instância do software capaz de servir a múltiplos clientes (tenants) simultaneamente.

No entanto, sistemas que utilizam Multitenancy enfrentam uma série de desafios, principalmente no que se refere à flexibilidade em atender os requisitos específicos de cada cliente na customização de processos, de fluxos e regras de negócio, e de interfaces com o usuário. Especificamente no problema de customização de interfaces, embora existam trabalhos na literatura relacionados à customização de interfaces Web, e existam implementações de mercado de mecanismos para possibilitar essas customizações, esses trabalhos e mecanismos ou não são projetados especificamente para sistemas Multitenant ou, quando são, não têm sua arquitetura publicada e seu código fonte disponíveis para serem reutilizados.

Assim, esta pesquisa investigou uma alternativa para a customização de interfaces Web no contexto de Software como Serviço Multitenant. Como resultado, foi inicialmente definido e implementado um mecanismo não intrusivo para o desenvolvimento de aplicações $M u l$ titenant chamado DORMT (Domain-Based Shared-Database Multitenancy), sobre o qual foi possível construir um mecanismo para a customização de interfaces Web, chamado MHT (Multitenant Hierarchical Themes), baseado no padrão MVC (Model-View-Controller) e nos conceito de temas e de hierarquias. 

The adoption of Software as a Service (SaaS) is growing worldwide, driven by the many advantages that this software distribution model offers to both service providers and their clients. In SaaS, the service provider is also responsible for the development and the execution of the software, enabling that choices be made in terms of system architecture in order to reduce the complexity and costs related to its development and operation.

However, Multitenant systems face a number of challenges, mainly related to flexibility in meeting specific customer requirements in customizing the system processes, flows, business rules and user interfaces. Specifically on the problem of user interface customization, although there are studies in the literature and products on the market that implement mechanism to allow such customizations, these studies and mechanism are not specific to Multitenant systems or the mechanism architecture and source code is not available to be reused.

Thus, this study investigated alternatives for Web interfaces customization in the context of Multitenant Software as a Service. As a result, a non intrusive mechanism, called DORMT (Domain-Based Shared-Database Multitenancy), was defined and implemented to allow the development of Multitenant applications, on top of which a mechanism for Web interfaces customization, called MHT (Multitenant Hierarchical themes), based on the MVC pattern, on the concepts of themes and of hierarchies, was built. 

1 Introdução 1

1.1 Desafios na adoção de SaaS . . . . . . . . . . . . . . . . . . . 3

1.2 Problema, Objetivo e Resultados . . . . . . . . . . . . . . . . 4

1.3 Organização da Dissertação . . . . . . . . . . . . . . . . . . 5

2 Background 7

2.1 Considerações Iniciais . . . . . . . . . . . . . . . . . . . . . . . 7

2.2 Software como Serviço e Multitenancy . . . . . . . . . . . . . . 9

2.2.1 Principais Características . . . . . . . . . . . . . . . 10

2.2 .2 Modelos de Negócio . . . . . . . . . . . . . . . . . . . . . . . . . . . . . . . . . . . . . 12

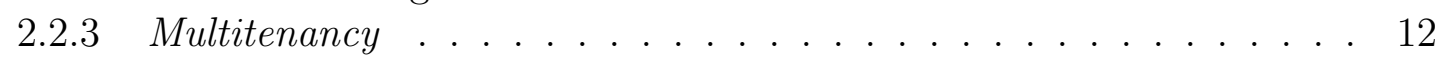

2.2.3.1 Tenant Resolution ... . . . . . . . . . . . 14

2.2.3.2 Data Partitioning . . . . . . . . . . . . . 16

2.2.3.3 Interação entre os componentes . . . . . . . . . . . . . . . . . . . . . . . . . .

2.2.3.4 Níveis de Maturidade . . . . . . . . . . . . . . . . . . . 17

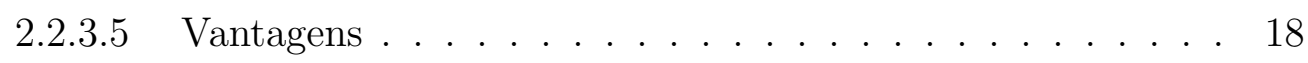

2.2.3.6 Desvantagens . . . . . . . . . . . . . . . . . 19

2.3 MVC: Model-View-Controller . . . . . . . . . . . . . . . . 22

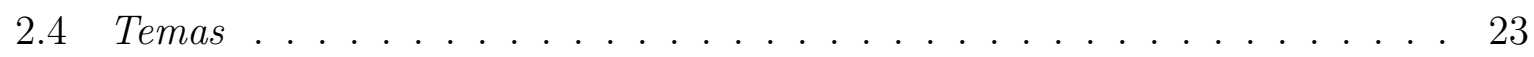

2.5 Trabalhos Relacionados . . . . . . . . . . . . . . . . . 24

2.6 Considerações Finais . . . . . . . . . . . . . . . . . . 26

3 Mecanismo de Referência para Multitenancy 29

3.1 Considerações Iniciais . . . . . . . . . . . . . . . . . . . . . . . . . . . . . . 29

3.2 Um Mecanismo não Intrusivo para Multitenancy . . . . . . . . . . . . . . 30

3.2.1 Um Tenant Resolver não Intrusivo . . . . . . . . . . . . . . . . . 31

3.2 .2 Um Data Partitioner não Intrusivo . . . . . . . . . . . . . . . . 34

3.2 .3 Mecanismo Proposto em Uso . . . . . . . . . . . . . . . 36

3.3 Considerações Finais . . . . . . . . . . . . . . . . . . . 37

4 MHT: Multitenant Hierarchical Themes 39

4.1 Considerações Iniciais . . . . . . . . . . . . . . . . . . . . . . . . . . . . . . . . . . . . . . . . . . . . . . . .

4.2 O mecanismo MHT . . . . . . . . . . . . . . . . . . 40 


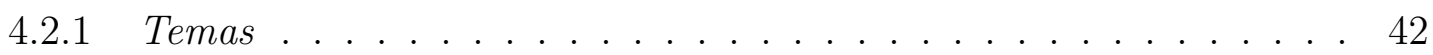

4.2 .2 Hierarquia de Temas . . . . . . . . . . . . . . . . . . . . . . 42

4.2 .3 Componentes do MHT . . . . . . . . . . . . . . . . . . . . . . . . 44

4.2.3.1 Theme Resolver . . . . . . . . . . . . . . . 45

4.2.3.2 View Resolver . . . . . . . . . . . . . . . . . . . . . 45

4.2.3.3 Assets Resolver . . . . . . . . . . . . . . . . . . 47

4.2.3.4 I18n Resolver. . . . . . . . . . . . . . . . . . . . . . 49

4.3 Mecanismo Proposto em Uso . . . . . . . . . . . . . . . . . . . . . . . . . . . . . . . . . . . 52

4.4 Boas práticas no uso do MHT . . . . . . . . . . . . . . . . 52

4.5 MHT: Pontos Fortes . . . . . . . . . . . . . . . . . . 55

4.6 MHT: Pontos Fracos . . . . . . . . . . . . . . . . . . 56

4.7 Considerações Finais . . . . . . . . . . . . . . . . . . 56

5 Discussões e Conclusão $\quad 59$

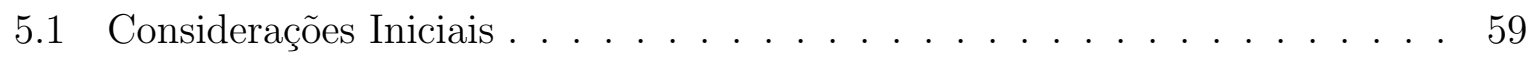

5.2 Oportunidades para Trabalhos Futuros . . . . . . . . . . . . . . 60

5.2.1 Trabalhos futuros em Multitenancy . . . . . . . . . . . . . . 60

5.2.2 Trabalhos futuros em Customização de Interfaces . . . . . . . . . . 61

5.3 Considerações Finais . . . . . . . . . . . . . . . . . . 62

$\begin{array}{ll}\text { Referências } & 67\end{array}$ 
2.1 Recursos Compartilhados em uma Aplicação Multitenant . . . . . . . . . . . 14

2.2 Funcionamento Sistema Multitenant com Banco de Dados Compartilhado . 15

2.3 Níveis de Maturidade em SaaS segundo Hudli et al. (2009) . . . . . . . . . 19

2.4 Níveis de Maturidade em SaaS segundo Zainuddin e Gonzalez (2011) . . . 20

2.5 Componentes do padrão MVC em sistemas Web . . . . . . . . . . . . . . . 22

3.1 Mecanismo não intrusivo para Multitenancy . . . . . . . . . . . . . . . 32

3.2 Exemplo de Tabela para Armazenar as Informações dos Ttenants . . . . . 33

3.3 Exemplo de Tabela com Dados Compartilhados pelos Tenants . . . . . . . 34

3.4 Exemplo de Tabela Multitenant . . . . . . . . . . . . . . . . 35

3.5 Exemplo de um tenant em um SaaS usando o mecanismo de Multitenancy 37

3.6 Exemplo de um segundo tenant em um SaaS usando o mecanismo de Mul-

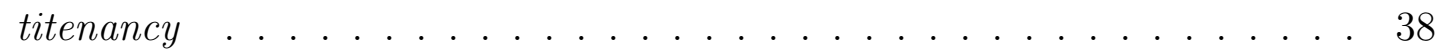

4.1 Extensão do padrão MVC no mecanismo MHT . . . . . . . . . . . . . . 41

4.2 Conteúdo de um Tema MHT . . . . . . . . . . . . . . . . . . . 42

4.3 Exemplo de Hierarquia de Temas no MHT . . . . . . . . . . . . . . . . . 43

4.4 Estrutura de diretórios para armazenar os arquivos dos Temas no MHT . . 45

4.5 Resolução de Views com MHT . . . . . . . . . . . . . . . . . . . . . . . 47

4.6 Resolução de Assets com MHT . . . . . . . . . . . . . . . . . . . . . . 48

4.7 Internacionalização de textos com $M H T$. . . . . . . . . . . . . . . . 50

4.8 Exemplo de um tenant usando um tema MHT . . . . . . . . . . . . . . . . 53

4.9 Exemplo de um segundo tenant usando um outro tema MHT . . . . . . . . 54

4.10 Exemplo de um tema usando o mecanismo de hierarquias do MHT . . . . 55 



\section{Lista de Tabelas}

2.1 Comparativo com Trabalhos Relacionados . . . . . . . . . . . 26

4.1 Exemplo de Hierarquia de Temas no MHT . . . . . . . . . . . . . . . . . 44

5.1 Comparativo com Trabalhos Relacionados . . . . . . . . . . . . . 60 



\section{Lista de Listagens}

3.1 Implementação de Tenant Resolver como um filtro em Ruby on Rails . . . 32

4.1 Implementação de View Resolver como um filtro em Ruby on Rails . . . . 46

4.2 Implementação do componente Assets Resolver em Ruby on Rails . . . . . 49

4.3 Implementação do componente I18N Resolver em Ruby on Rails . . . . . . 49

4.4 Configuração do componente I18N Resolver em Ruby on Rails . . . . . . . 51 

Lista de Abreviaturas e Siglas 


\begin{tabular}{|c|c|}
\hline API & Application Programming Interface \\
\hline ASP & Application Service Provider \\
\hline CMS & Content Management System \\
\hline CRM & Customer Relationship Management \\
\hline CSS & Cascading Style Sheets \\
\hline $\mathrm{DAO}$ & Data Access Object \\
\hline DOS & DenIal of Service \\
\hline DORMT & Domain-Based Shared-Database Multitenancy \\
\hline ERB & Embedded Ruby \\
\hline HTML & Hypertext Markup Language \\
\hline HTTP & Hypertext Transfer Protocol \\
\hline IaaS & Infrastructure as a Service (Infraestrutura como Serviço) \\
\hline ISV & Independent Software Provider \\
\hline Java EE & Java Platform Enterprise Edition \\
\hline JPA & Java Persistence API \\
\hline JSON & JavaScript Object Notation \\
\hline JSP & Java Server Pages \\
\hline JSR & Java Community Process \\
\hline LESS & Leaner CSS \\
\hline MHT & Multitenant Hierarchical Themes \\
\hline MVC & Model-View-Controller \\
\hline PaaS & Platform as a Service (Plataforma como Serviço) \\
\hline REST & Representational State Transfer \\
\hline SaaS & Software as a Service (Software como Serviço) \\
\hline SCSS & Syntactically Awesome Style Sheets \\
\hline SMB & Small and Medium Business \\
\hline SME & Small and Medium Enterprises \\
\hline SOA & Service Oriented Architecture \\
\hline SQL & Structured Query Language \\
\hline XaaS & Anything as a Service (Qualquer coisa como Serviço) \\
\hline XPath & XML Path Language \\
\hline XML & Extensible Markup Language \\
\hline XSL & Extensible Stylesheet Language \\
\hline XSLT & XSL Transformation \\
\hline
\end{tabular}


Software como Serviço, ou SaaS (do inglês, Software as a Service), é um modelo de distribuição de software que vem ganhando importância no Brasil e no mundo, alavancado pela expansão da Internet, das tecnologias web e de Cloud Computing (Cherobino, 2007) e pelas muitas vantagens que esse modelo oferece. No modelo SaaS o provedor do serviço também é responsável pelo seu desenvolvimento e execução o que, quando comparado a modelos de distribuição de software tradicionais baseados em licenças, traz vantagens tanto para os provedores, que podem tomar decisões relacionados a arquitetura e infraestrutura de execução de seu software para simplificar e reduzir custos, quanto para os clientes do serviço, que se beneficiam de menores custos, da não necessidade de alocar recursos próprios para manter o software e de atualizações frequentes do sistema.

Essa expansão é quantificada em alguns estudos, como em um levantamento do Gartner Group ${ }^{1}$ que analisou que o mercado de SaaS irá crescer a uma taxa de $19,5 \%$ ao ano entre 2011 e 2016, passando de um mercado de 13.5 para 32.8 bilhões de dólares dentro desse período (Rosenfield, 2013). Outras projeções indicam a possibilidade de que em 2016, mais de 50\% das ISVs (Independent Software Vendors) irão oferecer apenas soluções baseadas no modelo SaaS. No Brasil, que é considerado por empresas como a Saleforce.com ${ }^{2}$, pioneira no mercado de SaaS, um dos principais mercados para esse novo modelo (Antonelli, 2008), o interesse vem aumentando principalmente entre as pequenas e médias empresas (chamadas SBMs (Small and Medium Business) ou SMEs (Small and

\footnotetext{
${ }^{1}$ http: //www.gartner.com

${ }^{2}$ http://www.salesforce.com/br/
} 
Medium Enterprises)), que em 2007 representavam 60\% da população economicamente ativa do Brasil e geravam 21\% do produto interno bruto nacional (Cherobino, 2007), já que essas empresas geralmente não contam com recursos financeiros necessários para investir no desenvolvimento de software próprio com qualidade equiparável aos sistemas oferecidos pelos provedores SaaS.

Os sistemas construídos segundo o modelo SaaS têm características variadas, mas a que melhor os identifica e os diferencia de softwares tradicionais é a mudança na propriedade do software em si. No modelo tradicional, um software de determinado fornecedor é comprado ou licenciado por um cliente para ser instalado e executado pelo próprio cliente em sua infraestrutura, enquanto que no modelo SaaS o software pertence ao fornecedor do serviço. Assim, o fornecedor do serviço é responsável pelo seu desenvolvimento, manutenção, evolução e execução, enquanto que os clientes pagam uma taxa, geralmente a intervalos regulares, para utilizar o serviço. Em outra palavras, o cliente aluga o software do provedor, o que explica porque a alusão a locatários de imóveis é muitas vezes utilizadas para explicar o modelo comercial utilizado nos SaaS $\mathrm{S}^{3}$.

Na maioria dos casos, SaaS é distribuído para os clientes via Internet, para serem utilizados por meio de navegadores web, o que possibilita que provedores SaaS tenham um alcance global, sem a necessidade de lidar com problemas de logística de distribuição e de venda de seus produtos - outras vantagens incluem a redução de problemas relacionados à pirataria e a eliminação da necessidade de suporte à instalação e à execução do software. O modelo de distribuição SaaS permite que os provedores possam trabalhar com grande quantidade de clientes ao mesmo tempo em que têm custos menores de distribuição e de vendas - essas vantagens permitem que provedores possam fazer uso de novos modelos de negócio que visam obter lucro a partir de um grande volume de clientes, mesmo quando são cobrados preços mais baixos do que aqueles praticados por provedores de software tradicionais.

Para tirarem proveito do grande volume de clientes, provedores SaaS têm a seu favor o fato de controlarem totalmente o software e a infraestrutura que suporta o serviço que disponibilizam, de modo que podem fazer escolhas que diminuam seus custos e aumentem seus lucros. Com relação ao software, os provedores podem utilizar técnicas, arquiteturas e padrões de projeto que permitam ao seu sistema suportar um número cada vez maior de clientes ao custo de um aumento linear, ou mesmo sub linear, de gastos com infraestrutura. Com relação à infraestrutura utilizada para executar o software, os provedores podem se beneficiar da crescente oferta de serviços de Cloud Computing para alugar infraestrutura escalável e confiável a custos cada vez menores.

\footnotetext{
${ }^{3}$ a tradução de locatário para o inglês, tenant, é bastante utilizada em SaaS para referenciar os clientes dos serviços
} 
Dado que esses fatores trazem muitas vantagens tanto para o clientes quanto para os provedores dos serviços, o modelo SaaS tem se mostrado interessante tanto para empresas de desenvolvimento de software como para provedores de serviços de Internet que buscam atender principalmente o mercado de pequenas e médias empresas. Assim, o modelo tem sido utilizado não só por novas empresas que o utiliza para competir com empresas já estabelecidas que utilizam o modelo tradicional de venda de software, mas também por empresas já estabelecidas que passaram a considerar a transformação de seus produtos em SaaS.

\subsection{Desafios na adoção de SaaS}

Embora o modelo SaaS tenha várias vantagens quando comparado a modelos mais tradicionais de comercialização e distribuição de software, algumas de suas características têm impedido ou dificultado a adoção do modelo por alguns clientes. Uma pesquisa realizada pela Cutter Consortium ${ }^{4}$ levantou os principais problemas encontrados por empresas que já adotam o modelo (Kaplan, 2008). Segundo 46\% das empresas entrevistadas, a inabilidade de customizar a aplicação para atender suas necessidades é considerada como o maior problema com os sistemas SaaS que utilizam. Outros $23 \%$ das empresas consideram problemas de performance, baixa disponibilidade do serviço e tempos de respostas muito altos como os maiores problemas. Custos extras ou cobranças inesperadas são consideradas os maiores problema por $15 \%$ das empresas entrevistas. Ainda, $8 \%$ das empresas consideram a baixa qualidade no suporte ao cliente como o maior problema com os SaaS que utilizam.

O uso da arquitetura Multitenant, detalhada na Sessão 2.2.3, bastante utilizada no contexto de SaaS para permitir que uma única instância de um software possa atender a vários clientes simultaneamente (Rodrigues et al., 2012), traz vantagens aos provedores do serviço com relação à diminuição na complexidade de desenvolvimento, manutenção e execução do software, mas seu uso resulta em uma menor flexibilidade na customização de processos, fluxos de funcionamento, regras de negócio, e de interfaces com o usuário isso porque o mesmo código fonte é utilizado para atender a todos os clientes (Kabbedijk e Jansen, 2012). Especificamente no problema de customização de interfaces, o uso de Multitenancy dificulta que clientes do serviço possam se diferenciar de seus concorrentes, pois limita o que eles podem fazer em termos de aplicar sua marca e identidade visual à interface com o usuário, ou de criar uma melhor experiência do que aquela oferecida pelo provedor, requisitos importantes em sistemas utilizados para criar novos canais de

\footnotetext{
${ }^{4}$ http: //www. cutter.com/
} 
vendas e/ou comunicação com clientes, como lojas virtuais e sistemas de gerenciamento de conteúdo (do inglês Content Management System, CMS).

\subsection{Problema, Objetivo e Resultados}

A literatura reporta várias implementações que visam flexibilizar, em diferentes níveis, a customização de interfaces em sistemas web. Além disso, são vários os sistemas disponíveis no mercado com código fonte aberto, como por exemplo os CMSs Wordpress ${ }^{5}$,

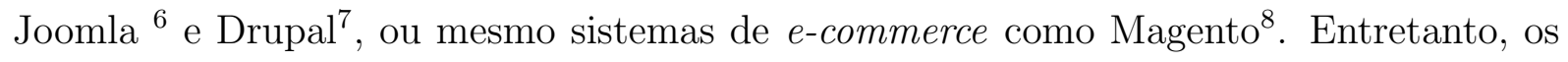
mecanismos implementados por esses sistemas não são projetados especificamente para o contexto de aplicações SaaS Multitenant de modo que, embora possam ser usados como base, não podem ser diretamente aplicadas a eles. Por outro lado, existem provedores SaaS que possuem recursos de customização de interfaces bastante completos e adequados a sistemas que utilizam Multitenancy, no entanto, esses provedores tendem a não compartilhar totalmente suas implementações desses mecanismos por ele constituir um diferencial comercial em relação a seus concorrentes e, embora seja possível analisar os recursos e características de seus mecanismos e como eles devem ser utilizados pelos clientes, a informação disponibilizada não é suficiente para replicar o mecanismo em outros sistemas.

Assim, o trabalho de mestrado aqui apresentado se desenvolveu no contexto de um dos principais problemas de customização no modelo SaaS: a customização de interfaces Web em sistemas SaaS Multitenant. Desse modo, o trabalho teve como objetivo propor uma solução alternativa para esse problema por meio de um mecanismo reutilizável e não intrusivo, que foi denominado MHT (Multitenant Hierarchical Themes) ${ }^{9}$, sendo baseado no padrão MVC (Model-View-Controller), no conceito de temas e no de hierarquias.

Como primeiro resultado, inicialmente um mecanismo base e não intrusivo para a implementação de Multitenancy em sistemas Web foi especificado e desenvolvido em diferentes linguagens de programação amplamente utilizadas atualmente: Ruby on Rails ${ }^{10}$ e Java ${ }^{11}$. A proposta e a arquitetura da implementação correspondente ao mecanismo foram reportados no artigo "A Nonintrusive Approach for Implementing Single Database, Multitenant Services from Web Applications"' (Manduca et al., 2014). Além disso, a implementação Java foi detalhada no artigo "Transforme aplicações web em serviços Multi

\footnotetext{
${ }^{5}$ http://wordpress.org/

${ }^{6} \mathrm{http}: / /$ www.joomla.org/

${ }^{7}$ http://drupal.org/

${ }^{8} \mathrm{http}: / /$ ww . magentocommerce.com/

${ }^{9}$ https://github.com/michetti/mht

${ }^{10}$ https://github.com/michetti/multi_tenancy

${ }^{11}$ https://github.com/michetti/icardapio/tree/multitenant
} 
Tenant' (Manduca, 2013). O desenvolvimento desse mecanismo foi necessário pela forte dependência que mecanismos que visam atacar problemas resultantes do uso do padrão Multitenant têm com os componentes base utilizados por esse padrão, como Tenant Resolver e Data Partitioner, descritos em mais detalhes no Capítulo 2.

A partir do mecanismo de Multitenancy foi especificado e desenvolvido o mecanismo de customização de interfaces MHT o qual, relacionado diretamente ao objetivo de pesquisa proposto, é o principal resultado do trabalho. O mecanismo MHT foi validado por meio de uma implementação na linguagem Ruby on Rails.

\subsection{Organização da Dissertação}

Nesta dissertação, o conteúdo dos demais capítulos é organizado como segue:

- O Capítulo 2 apresenta uma visão geral dos principais conceitos envolvidos no trabalho, como SaaS, Multitenancy, padrão MVC e temas, bem como uma discussão acerca de trabalhos relacionados.

- O Capítulo 3 define o mecanismo definido como referência para a implementação de sistema SaaS Multitenant.

- O mecanismo de referência é utilizado como base para a construção do mecanismo MHT, principal contribuição deste trabalho, como detalhado no Capítulo 4.

- O Capítulo 5 sumariza as contribuições do trabalho e discute trabalhos futuros. 



\subsection{Considerações Iniciais}

A venda de software como serviço não é um negócio novo. Já na década de 60, a IBM oferecia o poder de processamento e de armazenamento em banco de dados de seus mainframes como serviço ${ }^{1}$ em seus data centers em todo o mundo. O poder de processamento desses mainframes era vendido aos clientes que pagavam para executar suas aplicações por certo período de tempo (Wikipedia, 2012).

Nos anos 90, a expansão da Internet permitiu a criação de Application Service Providers (ASP): empresas responsáveis por hospedar, gerenciar e executar, de maneira centralizada, sistemas para outras empresas. Softwares gerenciados por ASPs são geralmente de autoria de terceiros, adquiridos por meio da compra de licenças, sendo que instalações independentes são feitas para cada cliente, geralmente em data centers de propriedade das próprias ASPs (Kim et al., 2012). Para as empresas clientes, a principal vantagem desse modelo está na terceirização de todos os aspectos necessários à operação do software, como a infraestrutura e o pessoal necessário para executar e manter o software em funcionamento, em troca do pagamento de uma taxa aos ASPs. Empresas do tipo ASP podem especializar seus funcionários em alguns poucos softwares com os quais irão trabalhar e contratar um número menor de funcionários, uma vez que os profissionais responsáveis por

\footnotetext{
${ }^{1}$ http://www-03.ibm.com/ibm/history/exhibits/dpd50/dpd50_chronology3.html
} 
manter a infraestrutura de hardware e os softwares oferecidos aos clientes são oferecidos a vários clientes ao mesmo tempo.

O modelo SaaS é essencialmente uma extensão do modelo ASP: a principal diferença é o fato de que no modelo SaaS o provedor é também o fabricante do sistema oferecido, sendo responsável pelo seu gerenciamento, desenvolvimento, evolução e execução. No modelo SaaS, o software é comercializado como um serviço, de modo que as taxas de administração e as licenças de software são geralmente substituídas por alguma forma de pagamento realizado periodicamente pelos clientes os quais, essencialmente, pagam um aluguel para utilizá-los (Nitu, 2009).

O fato de os provedores SaaS serem também os fabricantes dos softwares que comercializam dá vantagens a essas empresas, que podem fazer escolhas para diminuir os custos e a complexidade relacionados a vários aspectos do desenvolvimento do sistema e da infraestrutura necessária para mantê-lo em funcionamento. Com relação à infraestrutura para manter o serviço em funcionamento, grande parte dos provedores utilizam soluções de Cloud Computing com os quais podem alugar toda a infraestrutura necessária e distribuir o serviço de maneira centralizada pela Internet. Já com relação ao desenvolvimento do software em si, um padrão de arquitetura muito utilizada no contexto dos provedores SaaS é o Multitenant, de acordo com o qual uma mesma instalação do sistema é capaz de atender a uma série de clientes (tenants) simultaneamente, sendo o acesso e o armazenando os dados dos clientes realizado de forma particionada (Bezemer e Zaidman, 2010).

O uso de uma arquitetura que siga o padrão Multitenant traz uma série de vantagens aos provedores de serviço SaaS, mas também acarreta algumas desvantagens, principalmente no que se refere a uma menor flexibilidade na customização de processos, fluxos de funcionamento, regras de negócio e customização das interfaces com o usuário (Kumara et al., 2013). Considerando a customização de interfaces, por exemplo, a menor flexibilidade pode dificultar o uso do modelo SaaS em determinados cenários, como no caso em que se faz necessário aplicar a identidade visual e a marca da empresa na interface do usuário. A customização de interfaces se faz necessária para diferenciação entre as empresas clientes do SaaS, as quais são concorrentes entre si: esse é um requisito comum em sistemas utilizados para criar novos canais de vendas ou de comunicação com clientes, como lojas virtuais e CMSs.

Especificamente em relação ao problema da customização de interfaces, que é o foco deste trabalho, são reportadas na literatura (Chae et al., 2003; Kitano et al., 2010; Li et al., 2011; Yao et al., 2011) soluções simples as quais permitem um nível de customização limitado, baseadas na transformação da interface original do sistema, ou da definição de parâmetros para customizar atributos como cores, logotipos, textos e fontes. São encontradas também soluções mais complexas as quais possibilitam a definição de temas 
compostos por templates de interface, folhas de estilo (CSS), scripts javascript e imagens, e que permitem mudar totalmente a interface com o usuário, geralmente em soluções SaaS já no mercado, como por exemplo o mecanismo de temas dos SaaS Shopify ${ }^{2}$ e Bigcommerce ${ }^{3}$. No entanto, os provedores SaaS que implementaram esses recursos não disponibiliza todo o código fonte desses mecanismos, por se tratar de uma vantagem comercial frente a seus concorrentes e, embora seja possível estudar as funcionalidades que eles fornecem para customizar suas interfaces (e.g., como os temas devem ser feitos), não é possível estudar a arquitetura e a implementação que fazem o SaaS suportar o uso de temas. Por outro lado, sistemas de código aberto como os CMSs Wordpress ${ }^{4}$, Joomla ${ }^{5}$ e Drupal ${ }^{6}$, ou mesmo sistemas de e-commerce de código aberto como Magento ${ }^{7}$, que possuem mecanismos para a definição e utilização de temas, não seguem o modelo SaaS e, assim, não utilizam a arquitetura Multitenant, de modo que seus mecanismos de customização de interfaces, embora possam ser usados como base, não podem ser diretamente aplicadas em sistemas Multitenant e podem não ser adequadas para atender a escala de usuários que esses sistemas podem alcançar.

Diante desse cenário, este trabalho visa criar um mecanismo de código aberto, baseado no padrão MVC, para flexibilizar a customização de interfaces Web - mecanismo esse específico para SaaS que utilizem a arquitetura Multitenant. Assim, este capítulo visa introduzir conceitos fundamentais necessários para o entendimento do projeto como Software como Serviço, Multitenancy, o uso do padrão MVC em aplicações Web, e temas. Após a apresentação desses conceitos, trabalhos relacionados são discutidos.

\subsection{Software como Serviço e Multitenancy}

Software como Serviço ou SaaS (do inglês, Software as a Service) ${ }^{8}$ é um termo utilizado para definir sistemas que são distribuídos por provedores responsáveis pela criação, manutenção e execução desses sistemas, sistemas esses que são acessados por seus clientes por meio de navegadores Web, por exemplo, mediante pagamento de alguma taxa a intervalos regulares (Arya et al., 2010).

\footnotetext{
${ }^{2}$ http://www. shopify.com/Themes

${ }^{3}$ http: //www. bigcommerce.com/theme-store/

${ }^{4}$ http://wordpress.org/

${ }^{5}$ http: //www. joomla.org/

${ }^{6}$ http://drupal.org/

${ }^{7}$ http://www.magentocommerce.com/

${ }^{8}$ http://cloudtaxonomy.opencrowd.com/taxonomy/software-as-a-service/
} 
Essa definição classificaria como sistemas SaaS vários sistemas amplamente conhecidos, como por exemplo Google Search ${ }^{9}$, YouTube ${ }^{10}$, Wikipedia ${ }^{11}$, Twitter ${ }^{12}$ e Facebook ${ }^{13}$. Entretanto alguns autores classificam esses sistemas como Serviços de Internet, e utilizam a nomenclatura SaaS apenas no contexto de sistemas empresariais que auxiliam em tarefas específicas como contabilidade, recursos humanos, cobranças, service desk, gerenciamento de projetos, entre outros (Mäkilä et al., 2010). Ou seja, segundo esses autores, seriam exemplos de SaaS apenas sistemas como as Lojas Virtuais do UOL ${ }^{14}$, Shopify ${ }^{15}$, Basecamp $^{16}$, Granatum $^{17}$, Salesforce ${ }^{18}$, entre outros.

Este trabalho utiliza o termo SaaS no contexto mais geral que engloba as duas definições, por entender que sistemas em ambas as definições compartilham muitas características, tanto em seus modelos de negócios quando em seus aspectos técnicos. SaaS não deve ser confundido com SOA (Service Oriented Architecture), uma vez que SOA é um aspecto técnico de arquitetura e implementação de software e não como ele opera ou é distribuído para seus clientes. Existem SaaS que são implementados usando os princípios de SOA, mas isso não é um requisito.

O termo SaaS é considerado parte da nomenclatura de Cloud Computing, juntamente com Infraestructure as a Service ${ }^{19}$ (IaaS) e Platform as a Service ${ }^{20}$ (PaaS) (Banerjee et al., 2011). Atualmente existem tantos tipos diferentes de SaaS que subdivisões da nomenclatura começaram a ser utilizadas, como é o caso de Backup as a Service, Telephony as a Service, Communication as a Service, Monitoring as a Service, entre outros. Um generalização da nomenclatura é dada pelo termo Anything as a Service ${ }^{21}$ (XaaS) (Sengupta e Roychoudhury, 2011).

\subsubsection{Principais Características}

Existem algumas características recorrentes em SaaS, incluindo a utilização do serviço por meio de um navegador Web, a distribuição do serviço pela Internet, o foco em tornar a configuração inicial para a utilização do software simples, a ausência de necessidade de gerenciamento de recursos próprios de infraestrutura (servidores, backup, rede, no-breaks,

\footnotetext{
${ }^{9}$ http://www.google.com

${ }^{10}$ http://www . youtube.com/

${ }^{11}$ http://www. wikipedia.org/

${ }^{12}$ http://twitter.com/

${ }^{13}$ http://www.facebook.com/

${ }^{14}$ http: //www . uolhost. com.br/loja-virtual.html

${ }^{15}$ http://www. shopify.com/

${ }^{16}$ http://basecamphq.com/

${ }^{17}$ http://www.granatum.com.br/

${ }^{18}$ http://salesforce.com/

${ }^{19}$ http://cloudtaxonomy.opencrowd.com/taxonomy/infrastructure-as-a-service/

${ }^{20}$ http://cloudtaxonomy.opencrowd.com/taxonomy/platform-as-a-service/

${ }^{21}$ http://searchcloudcomputing.techtarget.com/definition/XaaS-anything-as-a-service
} 
etc.), as constantes atualizações e as melhorias nos processos e no software em si (quase sempre sem custos extras para os clientes), e a possibilidade de o cliente cessar o uso do serviço a qualquer momento. Além dessas características, um fator muito importante para o sucesso do modelo SaaS é baixo custo para clientes - quando comparado a softwares tradicionais que precisam ser adquiridos ou licenciados, e que demandam que seus clientes possuam infraestrutura própria para a execução contínua do serviço.

O baixo custo para os clientes que serviços SaaS normalmente oferecem são consequência de um conjunto de fatores, sumarizados a seguir (Ghaddar et al., 2012; Maluf et al., 2011):

- Um dos fatores é o uso da Internet e de navegadores Web para acesso ao serviço o que, além de tornar indivíduos e empresas de todo o mundo potenciais clientes, permite que o serviço alcance uma escala muito maior do que aquela alcançada por softwares tradicionais.

- Outro fator é consequência do fato de provedores de serviços SaaS não terem de lidar com problemas como logística e taxas de distribuição.

- Ainda outro fator é importante é a ausência da necessidade de suporte para que o cliente realize a instalação do software em sua própria infraestrutura.

- Outro fator que implica em custos menores é redução de pirataria, uma vez que o cliente não tem acesso nem ao código fonte da aplicação e nem ao código binário que seriam necessários para instalação e execução de um produto de software convencional.

- Um outro fator de baixo custo para clientes é o barateamento dos recursos computacionais como armazenamento e capacidade de processamento, consequência principalmente da expansão das tecnologias de Cloud Computing. Essas tecnologias permitem o oferecimento de infraestruturas como IaaS (Infraestrutura como Serviço) e PaaS (Plataforma como Serviço), que tornam possível que provedores de serviços SaaS possam alugar infraestruturas seguras e escaláveis a custos cada vez mais baixos.

- Ainda outro fator para o oferecimento de serviços a um custo baixo é o uso de arquiteturas de software escaláveis e de modelos de desenvolvimento ágeis, que permitem ao provedor do serviço minimizar os gastos com desenvolvimento, manutenção e execução de seus serviços.

Esse conjunto de fatores permite a provedores de serviço atenderem a um grande número de clientes simultaneamente, tornando possível o uso de modelos de negócio que 
se baseiam na escala da base de usuários para obterem lucro mesmo que preços menores sejam praticados — quando comparados a softwares tradicionais.

\subsubsection{Modelos de Negócio}

A escala de usuários alcançadas pelos provedores SaaS possibilita o uso de modelos de negócios diferentes dos tradicionalmente usados na comercialização de software, como a venda de licenças e de contratos de manutenção.

Um dos modelos mais utilizados por provedores SaaS é o de Subscrição, no qual cada cliente paga periodicamente uma taxa que dá direito ao uso do serviço, sendo que o pagamento pode ser, por exemplo, mensal ou anual. Uma variação desse modelo é o Fremimum, uma modalidade que oferece uma versão do serviço sem custo ou a um custo quase nulo (normalmente as funções mais básicas do serviço), e outra versão, completa, a um custo maior. Nesse modelo, a versão (quase) gratuita é oferecida para atrair novos clientes, na expectativa de que uma porção dos clientes venham a contratar o serviço completo. Nesse modelo, uma pequena porcentagem dos clientes pagantes (muitas vezes menos de $10 \%$ dos clientes) é suficiente para sustentar toda a operação do serviço (Boillat e Legner, 2013; Liao e Tao, 2008).

Outro modelo de negócio bastante conhecido é o baseado em propagandas (Ads Supported), no qual o provedor do serviço recebe seu pagamento de anunciantes que fazem propaganda para os clientes do serviço. Utilizam esse modelo a ferramenta de pesquisa do Google e o Facebook, entre outros.

Ter uma grande base de usuários cria outras fontes de receita para os provedores, como a criação de portais que agregam o conteúdo de todos os seus tenants. Nesse modelo, o provedor pode cobrar por serviços que agregam valor a seus clientes, como direcionar ou dar destaque para os produtos de determinado cliente, fornecer dados estatísticos e comportamentais dos usuários do serviço como um todo, entre outros.

\subsubsection{Multitenancy}

A tradução direta para o português do Brasil da palavra em inglês tenant é locatário. Essa palavra é comumente utilizada no ramo de imóveis para identificar a parte pagadora no aluguel de um imóvel, sendo que essa parte pode ser uma pessoa física, uma pessoa jurídica, entre outros. De forma similar, essa palavra é utilizada no contexto de SaaS para identificar a entidade ou cliente que paga para utilizar o software de um provedor por um período de tempo, podendo ser o cliente uma empresa, uma pessoa, ou um grupo de pessoas como uma família, por exemplo. 
Em um aluguel de imóvel tradicional, o locatário não é o dono do imóvel, ele apenas paga um valor previamente estabelecido para utilizar o imóvel por um certo período de tempo. Da mesma forma, em SaaS o proprietário do software é o provedor do serviço, enquanto que o tenant é apenas proprietário de dados dentro do sistema.

Como observado anteriormente, essa mudança na propriedade do software em SaaS traz várias implicações para ambos cliente e provedor do serviço. Do ponto de vista técnico, essa mudança permite que provedores tenham mais controle sobre como eles irão projetar, desenvolver, manter, evoluir e executar o software, permitindo a eles fazerem escolhas que possam diminuir os custos relacionados a essas atividade.

No contexto de infraestruturas SaaS, um padrão de projeto bastante utilizado para atender a um número possivelmente muito grande de clientes ao mesmo tempo que usa poucos recursos computacionais em SaaS é o chamado Multitenancy. Um software Multitenant é um sistema construído de tal forma que é capaz de servir múltiplos tenants ao mesmo tempo, ou seja, uma única instância de um software é capaz de identificar a qual tenant uma requisição pertence e processar uma resposta usando apenas os dados que pertençam a esse tenant (Weissman e Bobrowski, 2009), como ilustrado na Figura 2.1. Uma única instância pode corresponder a um único servidor executando o software que implementa o serviço, ou a um conjunto de recursos de infraestrutura incluindo clusters de servidores, bancos de dados, sistemas de mensagens, caches, entre outros, todos agindo em conjunto para executar um serviço escalável e seguro contra falhas (Liu et al., 2013; Schaffner et al., 2013).

Como ilustrado na Figura 2.1, um tenant representa um cliente do serviço e ele pode ser mapeado a diferentes entidades dependendo do contexto do serviço. Por exemplo, se um provedor oferece um serviço para o controle de finanças pessoais, uma tenant pode representar uma única pessoa, mas se o serviço oferece controle financeiro para empresas, um tenant pode representar essa empresa, com todos os seus funcionários e seus diferentes papéis na empresa.

Existem diferentes maneiras de se implementar uma aplicação Web Multitenant, mas sua arquitetura em alto nível geralmente compreende identificar o tenant a partir da requisição Web e então usar esse tenant para particionar os dados no mecanismo de persistência utilizado, 2.2. Essas duas etapas são comuns em diversas implementações de mecanismos para Multitenancy (Lee e Choi, 2012; Rodrigues et al., 2012) e serão identificadas neste trabalho respectivamente como Tenant Resolution (Figura 2.2 itens 1 e 2), detalhado na Sessão 2.2.3.1 e Data Partitioning (2.2 itens 3 e 4), detalhada na Sessão 2.2.3.2. 


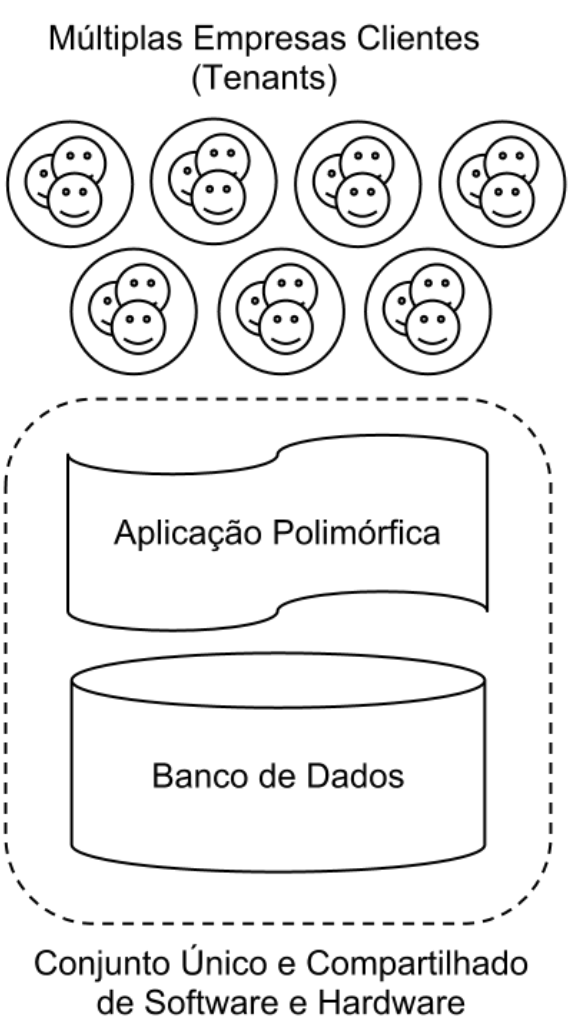

Figura 2.1: Uma aplicação Multitenant usa um mesmo conjunto de recursos de software e hardware para satisfazer as necessidades de múltiplas empresas clientes (adaptada de Weissman e Bobrowski (2009))

\subsubsection{Tenant Resolution}

A primeira etapa de uma aplicação Web Multitenant funcione deve determinar a qual tenant uma requisição Web corresponde, uma vez várias outras atividades da aplicação como interações com o banco de dados, customização da interface com o usuários, execução de processos de negócio customizados, entre outros, vão depender dessa informação.

O processo que determina o tenant é identificado neste trabalho como Tenant Resolution, enquanto que o componente que o implementa é chamado de Tenant Resolver. Existem diferentes estratégias que podem ser utilizadas para implementar esse mecanismo, mas em aplicações Web o tenant é derivado da requisição Web em questão, seja pela URL a que a requisição se refere ou por atributos do usuário autenticado, atributos esses obtidos a partir de dados da sessão a que a requisição se refere.

Quando o mecanismo é implementado a partir da URL, vários de seus atributos podem ser utilizados como identificador do tenant, como o subdomínio, um sufixo base do domínio ou mesmo domínios customizados para cada tenant. Uma combinação desses diferentes atributos também é possível, por exemplo, a identificação do tenant tanto por 


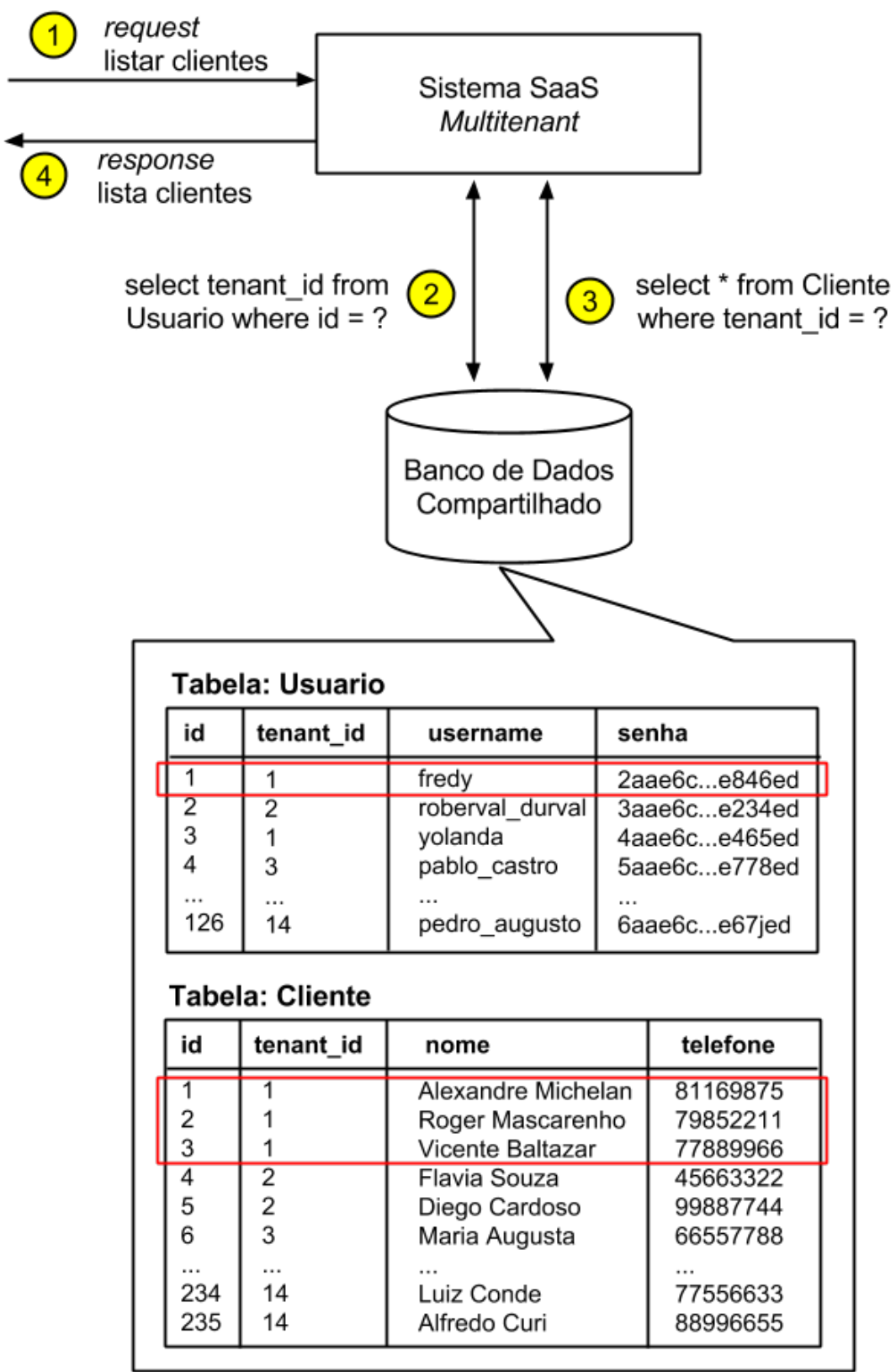

(1) Um usuário do Sistema SaaS solicita sua lista completa de clientes.

(2) Sistema obtém 'id' do usuário da sessão web, e consulta a tabela 'Usuario' para obter o 'tenant_id' correspondente.

(3) Sistema usa 'tenant_id' para particionar os dados, de modo a obter apenas os clientes desse tenant.

(4) Sistema responde com lista dos clientes do tenant.

Figura 2.2: Funcionamento Sistema Multitenant com Banco de Dados Compartilhado (conteúdo fictício) 
um subdomínio quanto por um domínio customizado (alguns provedores inclusive cobram valores extras de seus tenants para que eles possam usar seu próprio domínio).

\subsubsection{Data Partitioning}

A segunda etapa de uma aplicação Web Multitenant é o particionamento dos dados da aplicação entre cada tenant, como os dados no banco de dados e do cache de dados, as mensagens de processamento assíncrono, entre outros.

O processo correspondente, aqui chamado de Data Partitioning, é implementado pelo componente Data Partitioner. Esse componente também é responsável por não permitir que os dados de um tenant estejam acessíveis aos demais tenants, o que seria uma falha de segurança bastante grave.

Os dados dos vários tentants podem ser particionados de diferentes maneiras, mesmo considerando apenas o uso de bancos de dados relacionais. As maneiras mais comuns de se implementar esse particionamento são:

- Uso de um único banco de dados com uma coluna que identifica a qual tenant uma tupla em uma tabela se refere;

- Uso de um único banco de dados com diferentes esquemas para cada tenant;

- Uso de um único banco de dados mas com prefixos ou sufixos nos nomes de cada uma das tabelas;

- Uso de instâncias de bancos de dados totalmente apartadas entre os tenants.

Além disso, são possíveis também combinações desses mecanismos, como por exemplo:

- Uso de um único banco com uma coluna diferenciadora para um conjunto de tenants;

- Uso de um banco separado, a um custo maior, para um cliente com maiores restrições de segurança.

Cada estratégia tem suas vantagens e desvantagens. Por exemplo, quando múltiplos esquemas são usados, não é necessário (re)projetar os índices do banco de dados para incluir a coluna que identifica o tenant, além de ser pouco provável que os dados de um tenant sejam mostrados a usuários de outro tenant. Por outro lado, essa estratégia exige um esforço maior por parte do provedor do serviço, pois backups e mudanças da estrutura do banco de dados precisariam ser tratadas separadamente, aumentando os custos.

Já a estratégia que faz uso de um banco de dados único com uma coluna para identificar o tenant em suas tabelas torna mais fácil o gerenciamento e a evolução do schema do banco de dados em si, além de utilizar uma quantidade menor de recursos computacionais 
e, ainda, de facilitar a obtenção de dados analíticos sobre os dados do sistema como um todo. Por outro lado, no caso da evolução de aplicações existentes para aplicações multitentant essa estratégia requer, entre outros: uma mudança no esquema original no banco de dados, um tratamento dos índices para utilizar a nova coluna, mudanças nas consultas SQL (Structured Query Language) para adicionar a restrição de acesso ao dado tenant, além de, por alguma falha de projeto, haver a possibilidade de dados de um tenant serem apresentados a usuários de outros tenants.

\subsubsection{Interação entre os componentes}

Do ponto de vista de implementação, as tarefas de identificação do tenant e de particionamento dos dados de cada tenant são independentes: entretanto, elas precisam estar apropriadamente integradas para compor a funcionalidade desejada. O componente Data Partitioner precisa da identificação do tenant obtida pelo componenteTenant Resolver para executar as operações de particionamento corretamente. O compartilhamento da informação de identificação do tenant pode ser realizado de vários modos, mas um forma bastante utilizada é o uso da sessão do usuário na aplicação ou o uso da memória associada a thread que está sendo usada para atender a requisição do usuário.

\subsubsection{Níveis de Maturidade}

Este trabalho se realiza no contexto de pesquisas em configuração e customização de interfaces em SaaS com arquitetura Multitenant. Para que esses sistemas sejam viáveis, eles precisam permitir a adaptação das necessidades de diferentes clientes, e isso só é possível por meio das opções de configuração oferecidas pelo sistema (Arya et al., 2010; Kwok et al., 2008; Nitu, 2009; Sun et al., 2008). Alguns autores identificam cinco aspectos principais passíveis de configuração em um sistema SaaS (Arya et al., 2010), sendo eles:

- Interface: a configuração da interface com o usuário, como por exemplo a mudança de cores, logotipo, fontes, imagens, textos, entre outros.

- Fluxos: a configuração ou criação de fluxos e regras de negócio, para se adaptarem aos fluxos da empresa ou da localidade onde a empresa funciona.

- Dados: a configuração do modelo de dados, como a possibilidade de criação de novos campos.

- Controle de Acesso: a configuração de quais usuários podem executar quais tarefas, que pode ser diferente entre as várias empresas que utilizam o SaaS.

- Outros: configurações gerais, como a seleção de diferentes idiomas para clientes de diferentes localidades. 
Uma pesquisa realizada pela Cutter Consortium mostra que $46 \%$ das empresas entrevistadas consideram a inabilidade de customizar a aplicação para atender suas necessidades como o maior problema com os sistemas SaaS que utilizam (Kaplan, 2008). Diante de sua importância, alguns autores (Hudli et al., 2009) definem o grau de maturidade desses sistemas de acordo essas capacidades, como sumarizado na Figura 2.3:

- Nivel 1: O Software é customizado para cada cliente pelo provedor. Neste caso, é necessário que existam múltiplas instâncias do sistema: uma para cada tenant.

- Nivel 2: O Software oferece suporte mínimo a opções de configuração, de modo que ainda são necessárias múltiplas instâncias do sistema, mas em menor número quando comparadas ao Level 1.

- Nível 3: O Software provê um grande número de opções de configuração para suportar totalmente o padrão Multitenant, de modo que apenas uma instância do sistema serve a todos os tenant.

- Nível 4: O Software, além de ser Multitenant e totalmente configurável, é executado em ambiente que permite alta escalabilidade.

O estudo de Zainuddin e Staples (2011) mostra que existem opções de configuração em sistemas SaaS operadas pelos próprios provedores do serviço, e opções de configuração operadas diretamente por seus clientes. Esse mesmo estudo mostra que, com o passar do tempo e com o melhor entendimento do domínio de aplicação de seu SaaS e das reais necessidades de seus clientes, os provedores tendem a aumentar o número de opções de configuração acessíveis diretamente a seus clientes.

Zainuddin e Gonzalez (2011), em seu estudo de caso sobre configuração, maturidade e criação conjunta de valor em SaaS, agregam essa separação entre opções de configuração acessíveis ao provedor ou a clientes a classificação de maturidade definida por Hudli et al. (2009). Nessa nova classificação o Nível 3 passa a ser definido por sistemas SaaS que oferecem um grande número de opções de configuração, mas parte delas é controlada pelo provedor do serviço. O Nível 4 passa a classificar sistemas SaaS que são totalmente configuráveis diretamente pelos clientes. Um novo grau (Nível 5) é definido para classificar sistemas SaaS os quais, além de serem totalmente configuráveis pelos clientes, são executados em ambientes altamente escaláveis. A Figura 2.4 sumariza essa classificação.

\subsubsection{Vantagens}

O desenvolvimento de aplicações SaaS com a arquitetura Multitenant traz uma série de vantagens para os provedores de serviço, principalmente relacionados a diminuição dos 


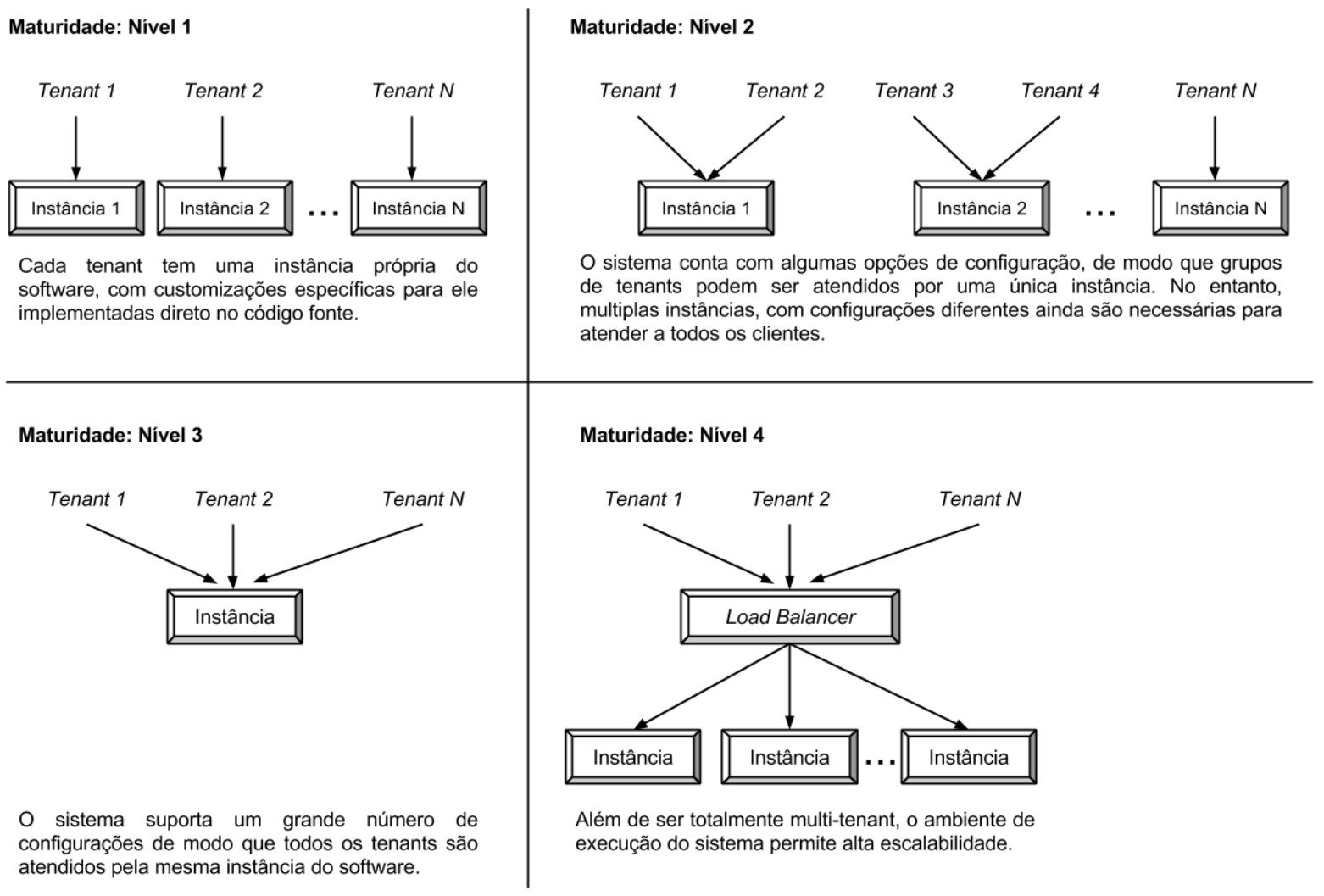

Figura 2.3: Níveis de Maturidade em SaaS segundo Hudli et al. (2009)

custo de operação por tenant, alcançada (a) pela redução da complexidade no gerenciamento do sistema; (b) pela redução dos gastos com infraestrutura; (c) pela demanda por um menor número de funcionários e de desenvolvedores; (d) pela eliminação do problema de pirataria; (e) pela não dependência de terceiros para a venda e distribuição do software, e (f) pela grande escala de clientes que esses serviços podem alcançar por serem distribuídos pela Internet.

O uso desse modelo também traz vantagens para os clientes, como (a) o pagamento periódico de pequenas taxas de utilização ao invés do pagamento, com antedecência, de licenças completas do software; (b) a possibilidade de poder parar de utilizar o sistema a qualquer momento; e (c) a eliminação da necessidade de contar com infraestrutura e pessoal próprio para manter o sistema em funcionamento.

\subsubsection{Desvantagens}

Embora a adoção do modelo SaaS e da arquitetura Multitenant estejam associados aos vários benefícios sumarizados na seção anterior, essa adoção também está associada a algumas desvantagens. Muitas dessas desvantagens afetam apenas certos nichos de mercado e estão relacionadas a características como a dependência da Internet e da terceirização 
Maturidade: Nivel 1

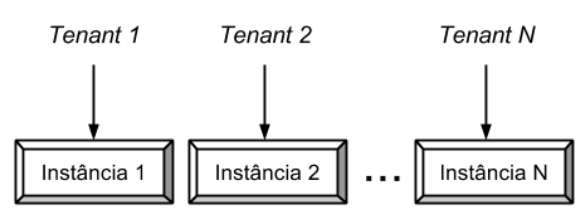

Cada tenant tem uma instância própria do software, com customizações específicas para ele implementadas direto no código fonte.
Maturidade: Nível 2

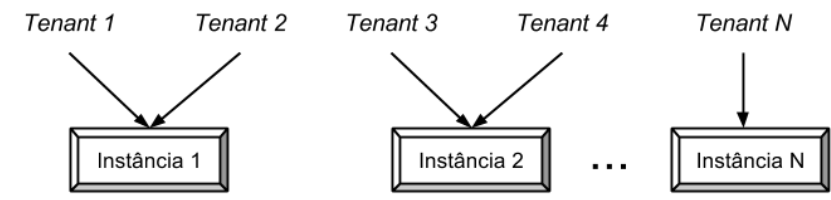

O sistema conta com algumas opções de configuração, de modo que grupos de tenants podem ser atendidos por uma única instância. No entanto, multiplas instâncias, com configurações diferentes ainda são necessárias para atender a todos os clientes.
Maturidade: Nivel 3

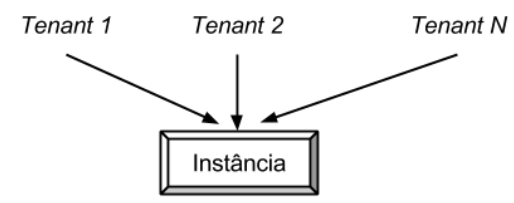

O sistema suporta um grande número de configurações de modo que todos os tenants são atendidos pela mesma instância do software. No entanto, apenas parte dessas configurações estão disponiveis aos tenants, enquanto que outras precisam ser configuradas pelo provedor do serviço .
Maturidade: Nivel 4

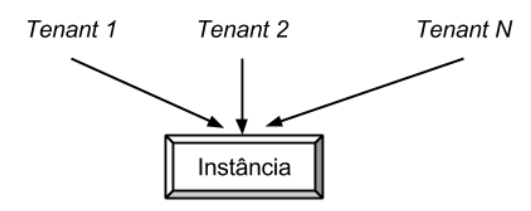

O sistema suporta um grande número de configurações de modo que todos os tenants são atendidos pela mesma instância do software.

Nesse ponto, todas as opções de configuração estão disponiveis diretamente aos tenants.

\section{Maturidade: Nivel 5}

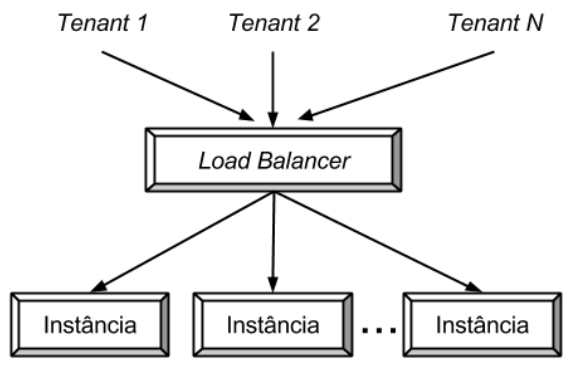

Além de ser totalmente multi-tenant, e totalmente configurável pelos tenants, 0 ambiente de execução do sistema permite alta escalabilidade.

Figura 2.4: Níveis de Maturidade em SaaS segundo Zainuddin e Gonzalez (2011)

da infraestrutura computacional, características essas que são justamente as principais vantagens nas aplicações SaaS, de modo que há casos em que essas desvantagens podem impedir completamente o uso do modelo.

Um dos principais problemas está relacionado à segurança e à privacidade dos dados dos usuários de um determinado tenant. Clientes como governos, instituições financeiras, instituições médicas, entre outros, têm restrições severas quanto à privacidade dos dados de seus clientes. Em SaaS, os dados são de propriedade dos tenants, mas o armazenamento, a segurança, a integridade e o controle de acesso a esses dados são de responsabilidade 
dos provedores, o que pode impedir que tais instituições usem os serviços - nesses casos a instituição tem que possuir o software e os dados sob sua própria guarda (on-permises).

Além disso, em alguns casos existem restrições quanto à localização geográfica dos servidores, como em algumas aplicações governamentais, os dados dos cidadãos devem ficar em território nacional, o que não é compatível com a hospedagem em núvem muitas vezes utilizadas pelos provedores SaaS, nos quais muitas vezes a localização física dos servidores não é conhecida nem mesmo pelo provedor do serviço.

Outro problema importante é a integração com sistemas legados e correspondente carga inicial de dados nos sistemas. Por serem acessadas via Internet e estarem instaladas em servidores de terceiros, aplicações que necessitam de volumes muito grandes de dados para operar podem ter a velocidade de transmissão ou possíveis problemas de segurança pela Internet como impedimentos para o uso de uma solução que segue o modelo SaaS. No caso de integração com sistemas on-permises, muitas vezes os provedores do serviço fornecem mecanismos para integração na forma de uma API (do inglês, Application Programming Interface) - entretanto, como essas APIs não são construídas especificamente para o sistema de cada cliente, nem todas as funções necessárias podem estar disponíveis. Ainda outro impedimento está relacionado ao fato de o sistema a ser integrado não ter acesso a Internet por ser usado apenas dentro da Intranet da empresa.

Impedimentos podem resultar de problemas relacionados à performance à estabilidade do serviço. De modo geral, um serviço SaaS deve ser projetado para ter alta disponibilidade e ser tolerante a falhas, ou seja, mesmo que um servidor falhe, o serviço deve continuar disponível e funcionando em um nível aceitável. Por se tratar de um único conjunto de recursos de infraestrutura computacional, um tenant pode ter uma taxa de utilização do serviço muito elevada quando comparada aos demais, e o sistema deve ser capaz de atender esse tenant sem prejudicar os demais, um problema conhecido como Tenant Placement (Elmore et al., 2013; Liu et al., 2013; Schaffner et al., 2013).

Além disso, o uso da arquitetura Multitenant torna mais complexa a customização do sistema para necessidades específicas dos tenants, no que se refere a processos de negócio, customização (ou branding) de suas interfaces, que trazem problemas na adoção de SaaS por marcas conhecidas ou por empresas que queiram manter sua identidade visual na aplicação, ou mesmo pela necessidade de um modelo de dados diferente do adotado pelo provedor do serviço.

Mesmo como todos esses potenciais problemas, a utilização do modelo SaaS vem crescendo no mundo todo, principalmente entre as pequenas e médias empresas, que não estão dispostas a abrir mão de algumas restrições em troca de menores custos ao mesmo tempo em que há flexibilidade e qualidade de serviço (Antonelli, 2008). É relevante observar, 
ainda, que esses potenciais problemas são justamente problemas de pesquisa na atualidade (Kaplan, 2008; Lisserman, 2010; Sun et al., 2008).

\subsection{MVC: Model-View-Controller}

O MVC (do inglês, Model-View-Controller) é um padrão de projeto para a implementação de interfaces com o usuário bastante utilizado por frameworks de desenvolvimento Web (Freeman, 2013). Proposto originariamente para a construção de aplicações Smalltalk (Krasner e Pope, 1988), ele evoluiu para atender a necessidade de aplicações Web, entre outras.

O padrão MVC se baseia na divisão de um determinado software em três camadas ou componentes com funções bem definidas, como pode ilustrado na Figura 2.5: o Modelo (Model), a Visão (View) e o Controlador (Controller) - esses componentes trabalham juntos para receber requisições dos usuários, realizar a tarefa associada à requisição, e montar a interface com a resposta correspondente.

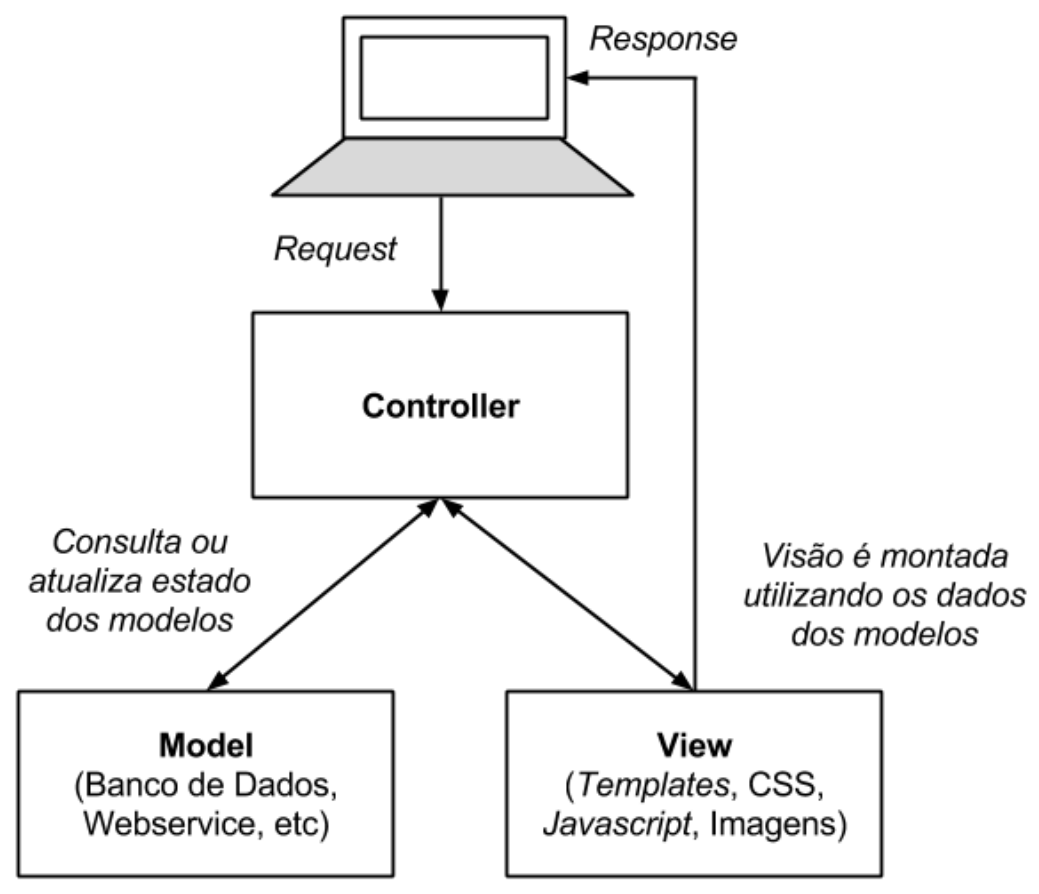

Figura 2.5: Componentes do padrão MVC em sistemas Web

Nesse padrão, o Modelo é o componente principal e é responsável pelos dados da aplicação e por suas regras de negócio. A Visão é o componente responsável pela apresentação da informação requisitada pelo usuário, sendo que em aplicações Web é geralmente composta por markup HTML, folhas de estilo CSS, arquivos Javascript, imagens, entre 
outros. O terceiro componente, o Controlador, é responsável por receber as requisições dos usuários, processá-las usando os métodos do modelo, para então construir as visões, que são retornadas para o usuário.

Além de definir os componentes, o padrão MVC também define a interação entre eles. O Controlador intermedia a comunicação entre Model e View, podendo utilizar os métodos disponibilizados pelos Modelos para atualizar seus estados e também pode interagir com métodos dos componentes de Visão para compor a representação visual desses Modelos. Em aplicações desktops, os Modelos podem notificar os Controladores associados a eles quando uma mudança de estado ocorre para que eles possam atualizar as Visões que compõem a representação visual dos modelos, embora em aplicações Web, que são baseadas no protocolo HTTP, normalmente os Controladores tenham que monitorar as mudanças de estado nos Modelos ao invés de receber notificações diretamente. As Visões interagem com os Controladores tanto para enviar dados submetidos pelos usuários, quanto para receber informações para montar as interfaces com esses usuários.

\subsection{Temas}

Embora não exista uma definição formal para o termo tema (do inglês, theme), algumas vezes também referenciado como skin ou template, ele é geralmente utilizado para descrever um conjunto de recursos utilizados para alterar a aparência e estrutura da camada de apresentação de um software (Piller e Tseng, 2010). Temas são encontrados tanto em softwares desktop quanto em softwares para a Web, sendo que no caso de sistemas Web os recursos que geralmente os compõem são arquivos para a geração de markup HTML, folhas de estilo CSS, imagens e arquivos Javascript.

Diversos sistemas oferecem suporte a temas, como por exemplo o sistema operacional Microsoft Windows ${ }^{22}$, o software para construção de apresentações Powerpoint ${ }^{23}$, os navegadores Google Chrome $^{24}$ e Mozzila Firefox ${ }^{25}$, tocadores de músicas como o Winamp ${ }^{26}$, diversos sistemas Web como a plataforma para blogs Wordpress $^{27}$ ou as plataformas de e-commerce como Magento ${ }^{28}$ e Shopify $^{29}$. Em grande parte dos casos, os temas são fornecidos ou comercializados separadamente do software em si sendo que, em casos como

\footnotetext{
${ }^{22}$ http://windows.microsoft.com/pt-br/windows/themes

${ }^{23} \mathrm{http}$ ://office.microsoft.com/en-us/templates/powerpoint-templates-FX102828209.aspx

${ }^{24}$ https://chrome.google.com/webstore/category/themes

${ }^{25}$ https://addons.mozilla.org/en-US/firefox/themes/

${ }^{26}$ http: //www. winamp.com/

${ }^{27}$ http://codex. wordpress.org/Theme_Development

${ }^{28}$ http://www .magentocommerce.com/design_guide/articles/how-magento-builds-content

${ }^{29}$ http://docs.shopify.com/themes/the-basics/build-your-theme
} 
o do Wordpress, existe uma grande variedade de temas desenvolvidos por empresas ou designers que ganham dinheiro customizando esses temas para usuários desses softwares.

Embora seu uso seja bastante comum na atualidade, temas são apenas um conceito, e não um padrão para o desenvolvimento de customizações de interface com o usuário. Desse modo, cada sistema implementa seu próprio mecanismo de temas e os designers e desenvolvedores que queiram desenvolve-los, precisam aprender os mecanismos de cada sistema.

\subsection{Trabalhos Relacionados}

Nesta seção estão sumarizados trabalhos relacionados diretamente à customização de interfaces em sistemas que seguem o modelo SaaS.

Kitano et al. (2010) mostram parte de um mecanismo para customização externa de interfaces em Software como Serviço previamente existentes. Customização externa corresponde ao reposicionamento dos elementos visuais de uma aplicação Web existente. O mecanismo, descrito brevemente pelos autores, consiste de um algoritmo que mapeia elementos visuais existentes em uma aplicação Web usando XPath ${ }^{30}$, uma mecanismo para descrever o reposicionamento, e outro mecanismo para gerar/executar as modificações nas interfaces. O problema de fato tratado pelos autores no artigo consiste em como obter essas expressões XPath de forma a minimizar problemas quando o sistema Web para o qual essas expressões foram escritas for modificado, utilizando um número limitado de páginas como entrada para o algoritmo. Embora esse trabalho seja focado na customização de interfaces Web no contexto de SaaS, customizações externas não permitem grandes modificações nas interfaces, como apontado pelos próprios autores.

Alguns autores propõem utilizar os recursos da especificação Java Portlets 1.0 (JSR 168) ${ }^{31}$. Portlets são componentes de interface independentes, que podem ser conectados a aplicações e configurados, e que são gerenciados e executados dentro de um Portal. Portlets produzem fragmentos de texto com markup, os quais são agrupados para compor as páginas. Portlets suportam diferentes estados, como visualização, edição e ajuda, além de diferentes modos de apresentação, como normal, maximizado e minimizado. Geralmente, cada Portlets é responsável por uma parte específica dentro da aplicação, e pode ser integrado por meio de interfaces similares àquelas utilizadas por Web Services. Em particular em termos de customização de interfaces:

- Li et al. (2011) propõem um mecanismo para customização de interfaces em SaaS de modo que cada tenant possa configurar quais funções do SaaS deseja utilizar por

\footnotetext{
${ }^{30}$ http://www.w3.org/TR/xpath/

${ }^{31}$ http://jcp.org/aboutJava/communityprocess/final/jsr168/
} 
meio da ativação ou desativação de Portlets específicos. Além disso, os autores propõem que sejam utilizados os recursos dos Portais para posicionar os Portlets dentro das páginas e, ainda, que sejam utilizados os modos de configuração dos Portlets para oferecer opções para alteração de cores e espaçamentos, entre outros. Como os próprios autores apontam, esse mecanismo precisa ser ainda estudado mais a fundo, já que cada Portlet precisa ter sua aparência configurada independentemente. Além disso, sua aplicação está restrita à plataforma Java, que implementam a especificação de Portlets.

- Uma abordagem similar à de Li et al. (2011), utilizando a tecnologia de Portlets e de Portais para possibilitar a customização de interfaces em SaaS, também foi estudada por Yao et al. (2011). Em seu trabalho, os autores argumentam que existem dois aspectos fundamentais na configuração de interfaces: configuração da aparência das páginas e configuração do conteúdo das páginas. Esses dois tipos de configuração demandam soluções para dois tipos de problemas: como descrever e armazenar as informações sobre essas configurações, e como criar, modificar e obter essas configurações em tempo de execução. A solução apontada por Yao et al. (2011) é armazenar a descrição dessas configurações em um arquivo XML e utilizar os recursos da especificação Portlets para seu gerenciamento em tempo de execução.

Alguns autores fazem uso de duas técnicas principais de customizações de interfaces Web para múltiplos dispositivos. A primeira se refere à geração de diferentes interfaces Web a partir do processamento dos dados das aplicações usando diferentes arquivos com especificações XSLT ${ }^{32}$ (XSL Transformations). A segunda se refere ao uso de técnicas de CSS e Javascript para criar layouts de interface fluidos, que adaptam a visualização dos elementos nas páginas Web de acordo com a resolução do dispositivo. Em particular:

- Chae et al. (2003) definem um mecanismo para separar lógicas de negócios dos dados da aplicação e da lógica de apresentação. Uma notação baseada em redes de Petri para mapear os processos de negócio e suas interações é definida, assim como uma extensão da XSLT para reconhecer essa notação e gerar as interfaces da aplicação. Embora o trabalho aborde a geração de interfaces usando XSLT, o artigo não trata da geração interfaces para diferentes dispositivos.

- Em seu trabalho, Wei et al. (2010) propõem a reutilização de software em sistemas nos quais a interface Web é baseada em XML, fazendo uso de documentos XSLTs para criar interfaces para dispositivos móveis. Esse mecanismo, no entanto, exige

\footnotetext{
${ }^{32}$ http://www.w3.org/TR/xslt
} 
que os sistemas representem seus dados em XML, e não trata dos impactos em performance causados pelo processo de geração desse XML e na posterior transformação nas interfaces para os dispositivos usando XSLTs.

Como apresentado, existem trabalhos que fazem referência à importância da customização de interfaces no contexto de SaaS - no entanto, apenas alguns estudos de fato exploram o problema (Kitano et al., 2010; Li et al., 2011; Yao et al., 2011). A Tabela 2.1 relaciona todos esses trabalhos e as Tecnologias utilizadas pelos autores às características desejáveis em um mecanismo de customização de interfaces, como o suporte a customizações Simples na interface como mudanças de cores, fontes e/ou partes da estrutura das páginas, o suporte a customizações Complexas como a mudança completa de todos os elementos que compõem a interface com o usuário, o suporte a customizações desenvolvidas por Terceiros como o próprio cliente ou designers especializados e por fim, se o mecanismo proposto é disponibilizado com código Aberto para ser utilizado em outros projetos.

Tabela 2.1: Comparativo com Trabalhos Relacionados

\begin{tabular}{|c|c|c|c|c|c|}
\hline Quem & Tecnologia & Simples & Complexas & Terceiros & Aberto \\
\hline Kitano el al. (2010) & XPath & SIM & $\mathrm{NAO}$ & $\mathrm{NAO}$ & $?$ \\
\hline Li et al. (2011) & Java Portlets & SIM & NÃO & $\mathrm{NAO}$ & $?$ \\
\hline Yao et al. (2011) & Java Portlets & SIM & $\mathrm{NA} \tilde{O}$ & $\mathrm{NAOO}$ & $?$ \\
\hline Chae et al. (2003) & Redes Petri + XSLT & SIM & NÂO & NAO & $?$ \\
\hline Wei et al. (2010) & $\mathrm{XML}+\mathrm{XSLT}$ & SIM & $\mathrm{NAO}$ & $\mathrm{NAOO}$ & $?$ \\
\hline Shopify & Temas & SIM & SIM & SIM & $\mathrm{NA} \tilde{O}$ \\
\hline$\ldots$ & $?$ & SIM & SIM & SIM & SIM \\
\hline
\end{tabular}

O SaaS Shopify foi adicionado na tabela por suportar a maioria dos requisitos desejáveis na customização de interfaces, embora não tenha todo o código fonte de seu mecanismo de customização de interfaces disponível como código aberto, ou mesmo como produto de mercado para ser comprado e utilizado por outras empresas, por esse mecanismo constituir uma vantagem comercial para esse provedor em relação aos demais. Já a última linha mostra todas as características desejáveis para um mecanismo de customização de interfaces em SaaS.

\subsection{Considerações Finais}

Neste capítulo foram sumarizados os principais conceitos relacionados ao desenvolvimento do trabalho. Foi discutida também, com base em uma revisão de trabalhos relacionados, 
a oportunidade e a necessidade de um mecanismo para customização de interfaces no modelo SaaS. Os próximos capítulos apresentam o projeto e o desenvolvimento da solução proposta neste trabalho. 



\subsection{Considerações Iniciais}

O desenvolvimento do trabalho identificou a clara a dependência que o mecanismo de customização de interfaces tem da implementação do padrão Multitenancy utilizada pelo SaaS no qual seria utilizado. Em várias etapas de seu funcionamento, o mecanismo de customização de interfaces precisaria interagir com os componentes responsáveis pela resolução do tenant a partir da requisição Web (Tenant Resolver) e pelo particionamento de dados da aplicação (Data Partitioner).

De fato, qualquer mecanismo que vise atacar os problemas intrínsecos ao uso do padrão Multitenancy - como customização de processos, isolamento de execução, segurança de dados, entre outros - precisa interagir com os componentes fundamentais do padrão Multitenancy. No entanto, embora Multitenancy seja um padrão de desenvolvimento de software, não existe uma única forma de implementá-lo, tornando mais complexa a especificação de mecanismos que dele dependam, seja conceitual ou tecnicamente.

Dessa forma foi necessário, no contexto deste trabalho, propor uma especificação de implementação de referência para um mecanismo de Multitenancy que fosse não intrusivo e que pudesse ser implementado em diferentes linguagens de programação e frameworks de desenvolvimento Web amplamente utilizados atualmente. Assim, a especificação da 
implementação de referência, e sua correspondente implementação, visam permitir que mecanismos de customização de interfaces ou de processos, entre outros, possam ser especificados e implementados. A especificação e as características desse mecanismo de Multitenancy são apresentados neste capítulo — que como resultado as escolhas de design é denominado DORMT ${ }^{1}$ SaaS, como referência à Domain-based shaRed-database MultiTenancy SaaS.

\subsection{Um Mecanismo não Intrusivo para Multitenancy}

Multitenancy é um padrão de projeto que pode ser utilizado por aplicações nos mais diversos contextos, de modo que não é possível definir uma implementação do padrão capaz de suprir os requisitos de todos os tipos de infraestruturas SaaS. Dessa forma, o mecanismo aqui proposto deve ser implementado de maneira a não interferir com o código específico das aplicações no qual for utilizado, nem com as regras de negócio dessas aplicações. Além disso, o mecanismo proposto foi projetado de forma a poder ser implementado em linguagens de programação e frameworks de desenvolvimento Web utilizados atualmente no estado da prática, e de maneira a poder ser componentizado e reutilizado em múltiplas aplicações.

Dado que uma aplicação Multitenant precisa que dois componentes principais trabalhem juntos para, primeiro, identificar o tenant e, então, utilizar essa identificação para particionar os dados da aplicação, as sessões a seguir irão detalhar como cada um desses componentes podem ser implementados de forma não intrusiva, usando recursos comuns à maioria das principais linguagem de programação, ou disponíveis por meio de bibliotecas ou frameworks.

Como apresentado no Capitulo 2, a implementação desses componentes pode utilizar diferentes estratégias. Por exemplo, o Tenant Resolver poderia se basear em dados da URL requisição Web como domínio, subdomínio ou prefixo para identificar o tenant, ou mesmo obter o identificador do tenant a partir do cadastro do usuário no sistema, após esse efetuar o login na aplicação. Já o Data Partitioner poderia particionar os dados dos usuários utilizando um conjunto diferente de tabelas com o tenant_id como prefixo ou sufixo para cada tenant, poderia usar schemas diferentes para cada tenant no case de esse recurso ser suportado pelo sistema gerenciador de banco de dados, poderia utilizar instalações completamente separadas de banco de dados para cada tenant, ou mesmo particionar os dados das tabelas Multitenant utilizando colunas de diferenciação que armazenam e referenciam o tenant_id a que uma determinada tupla se refere.

\footnotetext{
${ }^{1}$ https://github.com/michetti/multi_tenancy
} 
Cada uma dessas estratégias tem suas vantagens e desvantagens. O mecanismo proposto faz escolhas claras quanto à forma como esses componentes serão implementados, de modo que sua especificação deve ser analisada caso a caso para avaliar se é a mais adequada ao problema que se deseja atacar. No mecanismo proposto, especificado e implementado:

- O componente Tenant Resolver utiliza o domínio e o subdomínio da requisição Web para identificar o tenant ao qual a requisição se refere, e

- o componente Data Partitioner utiliza colunas de diferenciação nas tabelas que armazenam os dados de múltiplos Tenants de modo compartilhado.

Como resultado dessas escolhas, o mecanismo proposto é chamado DORMT SaaS, como referência à Domain-based shaRed-database MultiTenancy SaaS.

Além da apresentação desses componentes, as próximas seções também detalham passos adicionais necessários para a configuração da aplicação que deseja utilizar o mecanismo DORMT. A Figura 3.1 ilustra a arquitetura em alto nível de uma aplicação que faz uso do mecanismo DORMT.

O mecanismo DORMT foi implementado em Java (Manduca, 2013), e em Ruby on Rails. Para referência, alguns dos principais elementos do código da implementação Ruby on Rails são também apresentados nas próximas seções.

\subsubsection{Um Tenant Resolver não Intrusivo}

Muitas linguagens de programação e frameworks como Java $\mathrm{EE}^{2}$ e Ruby on Rails ${ }^{3}$ suportam o conceito de filtros. Filtros são partes de código que podem ser executadas antes, depois ou ao redor de cada requisição Web. Eles geramente têm acesso à requisição em si e a seus parâmetros como a URL que foi requisitada e a outros recursos da aplicação, como a sessão do usuário, banco de dados, caches, entre outros.

Dessa forma, um componente Tenant Resolver não intrusivo pode ser implementado usando filtros para:

- Interceptar a requisição Web e analisar a URL que foi requisitada (Figura 3.1(A)) de modo a extrair informações como o domínio ou subdomínio da requisição para serem utilizados como identificadores do tenant ao qual a requisição se refere;

- De posse do identificador do tenant, o filtro obtém do banco de dados a entidade que representa o tenant na aplicação (Figura 3.1(B));

\footnotetext{
${ }^{2}$ http://www.oracle.com/technetwork/java/javaee/overview/

${ }^{3}$ http://rubyonrails.org/
} 


\section{URL requisitada:}

http://tenant1.mysaass.com

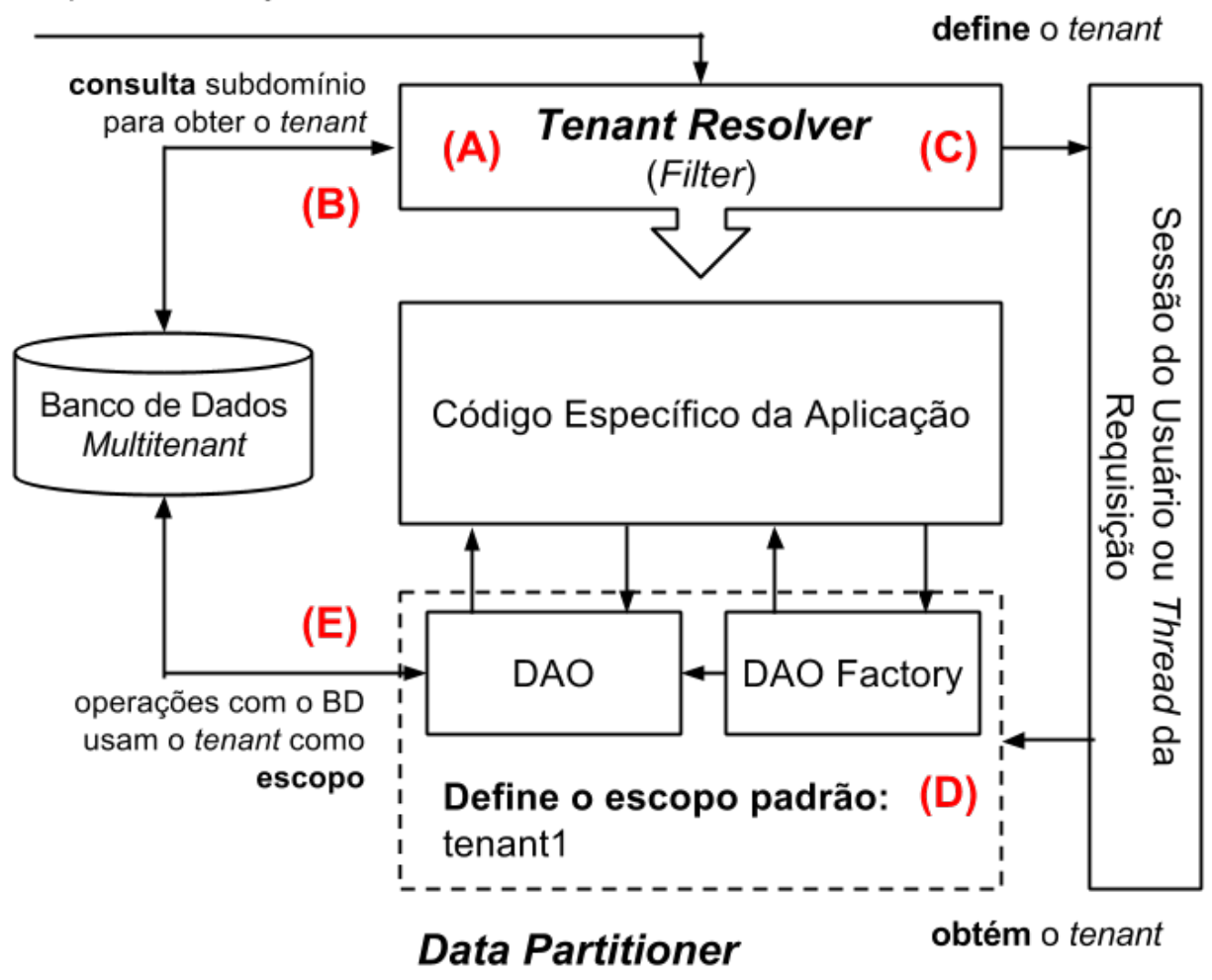

Figura 3.1: Mecanismo Não Intrusivo para Multitenancy: DORMT (Domain-based shaRed-database Multi Tenancy SaaS)

- O filtro então a disponibiliza para o restante da aplicação durante o fluxo daquela requisição (Figura $3.1(\mathrm{C})$ ).

Por exemplo, quando uma requisição para http://lets.rentcars .com chega ao servidor, o Tenant Resolver utiliza o subdomínio lets como identificador do tenant para consultar a tabela no banco de dados que contém as informações de todos os tenants, filtrando o resultado pelo identificador do tenant correspondente à requisição recebia. A Figura 3.2 mostra um exemplo de uma tabela que armazena as informações dos tenants.

É importante notar que essa tabela também pode ser utilizada para guardar outros dados específicos dos tenants como por exemplo Nome, Slogan, Informações de Cobrança, etc. Além disso, a coluna ID dessa tabela pode ser utilizada como o identificador interno do tenant no sistema, sendo referenciada pelas colunas tenant_id nas demais tabelas com dados Multitenant do sistema.

A Listagem 3.1 mostra uma implementação de referência do Tenant Resolver como um filtro na linguagem Ruby on Rails, referente a Figura 3.1 (A), (B) e (C).

Listagem 3.1: Implementação de Tenant Resolver como um filtro em Ruby on Rails 


\begin{tabular}{|l|l|l|l|}
\hline \multicolumn{1}{|c|}{ id } & \multicolumn{1}{|c|}{ nome } & \multicolumn{1}{c|}{ domínio } & \multicolumn{1}{c|}{ subdomínio } \\
\hline 1 & Lets Rent a Car & lets.com.br & lets \\
\hline 2 & Localiza & localiza.com.br & localiza \\
\hline 3 & Unidas Rent a Car & unidas.com.br & unidas \\
\hline
\end{tabular}

Figura 3.2: Exemplo de Tabela para Armazenar as Informações dos Tenants

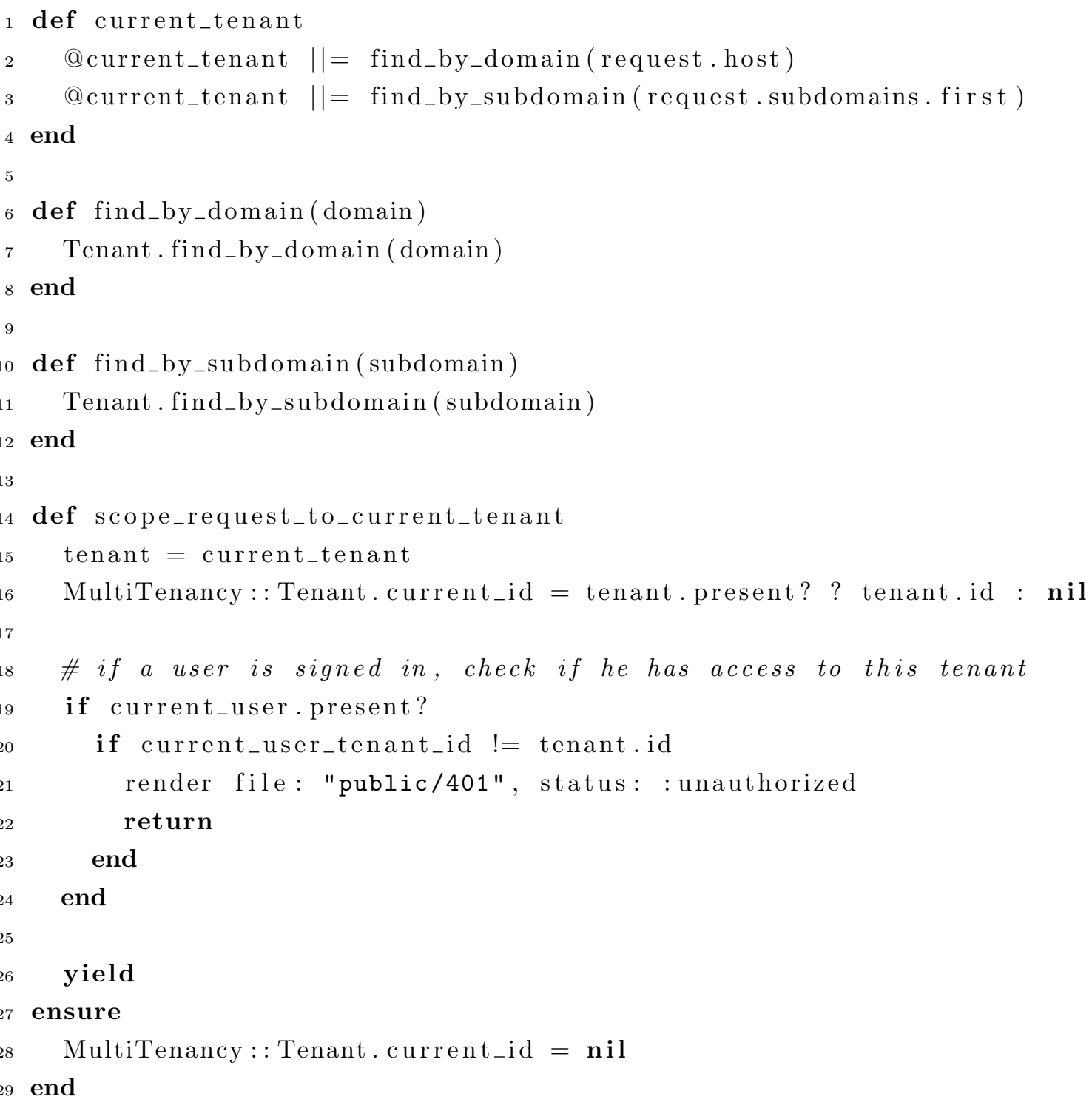




\subsubsection{Um Data Partitioner não Intrusivo}

A principal função do componente Data Partitioner é particionar os dados existentes no banco de dados do SaaS de acordo com o tenant identificado pelo componente Tenant Resolver, de maneira que as operações de inserção, atualização, remoção e busca no banco de dados operem apenas nos dados do tenant identificado para aquela requisição Web. O chamado "vazamento" de informações de um tenant para os demais ${ }^{4}$ corresponderia a um grave problema de segurança para o provedor SaaS, principalmente dependendo do ramo de atividade dos clientes do serviço. Erros na implementação desse mecanismo podem acarretar desde a perda de clientes pela falta de confiabilidade no provedor até a ocorrência de disputas judiciais em casos de vazamento de informações importantes.

Desse modo, a implementação de um mecanismo de particionamento não intrusivo, que possa ser componentizado e reutilizado ao longo da aplicação, traz vantagens para o provedor, por diminuir as chances de os desenvolvedores cometerem erros ao implementar o particionamento dos dados em cada operação com o banco de dados.

O mecanismo DORMT se baseia no particionamento de dados por meio do uso de colunas de diferenciação em tabelas que armazenam dados Multitenant. Nesse tipo de particionamento de dados, existem tanto tabelas com dados compartilhados entre todos os tenants quanto tabelas com dados particionados entre os tenants por meio da coluna de diferenciação. Para ilustrar esse mecanismo, seja o exemplo de uma infraestrutura SaaS fictícia para o aluguel de carros. Nesse sistema existe uma tabela com o cadastro de todos os fabricantes de veículos, como ilustrado na Figura 3.3.

\begin{tabular}{|l|l|}
\hline \multicolumn{1}{|c|}{ fabricante_id } & \multicolumn{1}{c|}{ nome } \\
\hline 1 & Volkswagen \\
\hline 2 & Hyundai \\
\hline 3 & Fiat \\
\hline
\end{tabular}

Figura 3.3: Exemplo de Tabela com Dados Compartilhados pelos Tenants

Nesse sistema também existe uma tabela com o inventário dos veículos que cada tenant possui, conforme ilustrado na Figura 3.4. Nessa tabela, existe uma referência para os dados da tabela de fabricantes compartilhada entre os tenants e, mais importante, existe uma coluna chamada tenant_id, que identifica a qual tenant aquela tupla pertence.

Existem diferentes maneiras de construir um componente para particionar esses dados. Um padrão de projeto bastante utilizado para abstrair a interação com os mecanismos de

\footnotetext{
${ }^{4} \mathrm{em}$ inglês geralmente referenciado como data leakage
} 


\begin{tabular}{|l|l|l|l|l|}
\hline fabricante_id & \multicolumn{1}{|c|}{ modelo } & ano & valor_aluguel & tenant_id \\
\hline 1 & Gol 1.0 16V & 2013 & 100.00 & 1 \\
\hline 1 & Gol 1.6 16V & 2012 & 120.00 & 2 \\
\hline 2 & i30 2.0 & 2012 & 200.00 & 2 \\
\hline
\end{tabular}

Figura 3.4: Exemplo de Tabela Multitenant

armazenamento de dados nas aplicações é o DAO (Data Access Object). Nesse padrão, a interação com o mecanismo de armazenamento de dados é feita por meio de operações definidas em uma API ou interface abstrata, da qual são construídas implementações concretas. Uma implementação ad-hoc para implementar um mecanismo de particionamento de dados seria alterar essas APIs e interfaces dos DAOs para que o tenant referente a cada requisição fosse passado como parâmetro, e então mudar as implementações para modificar as interações com o banco de dados para levar esse novo parâmetro em consideração - por exemplo por meio da inclusão de cláusulas where nas interações com um sistema de banco de dados. No entanto, mesmo estando restritas apenas aos DAOs, esse mecanismo demanda muitas mudanças na aplicações e portanto não pode ser considerado como uma forma não intrusiva de implementação de um Data Partitioner.

Outra prática comum em aplicações Web na atualidade é o uso de frameworks que permitem a interação com bancos de dados por meio de representações de suas tabelas e dados como classes e objetos. São exemplos desse mapeamento objeto-relacional frameworks como JPA (Java Persistence API) em Java EE, e o Active Record ${ }^{5}$ em Ruby on Rails. Esses frameworks visam facilitar a interação com os bancos de dados por meio da abstração das interações entre os objetos - entretanto, no final, eles precisam converter as operações em instruções conhecidas pelos bancos de dados, geralmente fazendo uso da linguagem SQL. No entanto, essas abstrações geralmente oferecem funcionalidades extras, sendo que uma delas é a definição de escopos-padrão sobre os quais as operações com os banco de dados devem ser executadas. A definição desses escopos-padrão corresponde a adição de cláusula where a cada operação realizada no banco de dados.

Essa última abordagem é a adotada no mecanismo DORMT, como ilustrado na Figura 3.1. Assim,

- uma maneira não intrusiva de implementar um Data Partitioner seria o uso desse tipo de framework para interagir com o banco de dados e a criação e uso de um escopo padrão baseado na coluna de identificação do tenant. Dessa maneira, bastaria

\footnotetext{
${ }^{5}$ https://github.com/rails/rails/tree/master/activerecord
} 
obter a entidade requisitada para interagir com o banco de dados, e configurar esse escopo padrão utilizando o tenant obtido a partir da requisição Web (Figura 3.1(D)).

- Para tornar o mecanismo ainda menos intrusivo, é possível utilizar o padrão de projetos conhecido como Factory para encapsular a obtenção das entidades que interagem com o banco de dados. Nesse padrão, uma factory é responsável por retornar as entidades já configuradas, nesse caso, obtendo o tenant e o definindo no parâmetro do escopo padrão da entidade (Figura 3.1(E)).

\subsubsection{Mecanismo Proposto em Uso}

Com o Tenant Resolver e Data Partitioner definidos, ainda existem algumas porções da aplicação que precisam ser customizadas como modificações no schema do banco de dados, modificações nos índices utilizados pela aplicação e a identificação de qual tabela irá conter dados Multitenant. Além disso, embora não seja diretamente explicado nesta seção, é preciso rever as chaves utilizadas em sistemas de cache como memcached, e adicionar o tenant_id como atributo ou cabeçalho em mensagens trocadas em sistemas de mensageria como JMS em Java EE.

As mudanças no schema do banco de dados que utilizará este mecanismo precisa incluir as colunas de diferenciação nas tabelas Multitenant da aplicação e adicionar a tabela para armazenar os dados dos tenants. A forma como isso deve ser feito depende fortemente do ambiente no qual a aplicação está sendo executada, podendo ser feita diretamente com scripts no banco de dados, ou utilizando recursos como migrations no framework Ruby on Rails, ou a atualização automática do schema do banco de dados em sistemas como JPA ou Hibernate em Java EE.

A identificação de quais tabelas no banco de dados irão conter dados Multitenant pode ser obtida com o uso de metadados, como annotations em Java, para marcar as classes que correspondem às tabelas Multitenant e também qual atributo corresponde a identificação do tenant. Esses metadados precisam então ser considerados no Data Partitioner para que apenas as entidades marcadas como Multitenant tenham seus dados particionados.

Outra mudança diz respeito a escalabilidade e a performance. Uma vez que todas as consultas ao banco de dados em tabelas Multitenant irão, na grande maioria das vezes, filtrar os dados baseados na coluna de diferenciação dos tenants, é importante que ela seja indexada e também adicionada aos índices já existentes na aplicação.

Para exemplificar o resultado final do mecanismo proposto em uso, um SaaS para a criação de lojas virtuais para restaurantes foi implementado e tem seu código fonte disponível para ser usado como referência ${ }^{6}$. A Figura 3.5 apresenta a página inicial desse

\footnotetext{
${ }^{6}$ https://github.com/michetti/deliveryme
} 
sistema, para um tenant identificado pelo subdomínio habbibs, exibindo apenas os dados desse tenant, enquanto que a Figura 3.6 mostra a mesma página inicial nesse mesmo sistema, mas para um segundo tenant, identificado pelo subdomínio pizzahut.

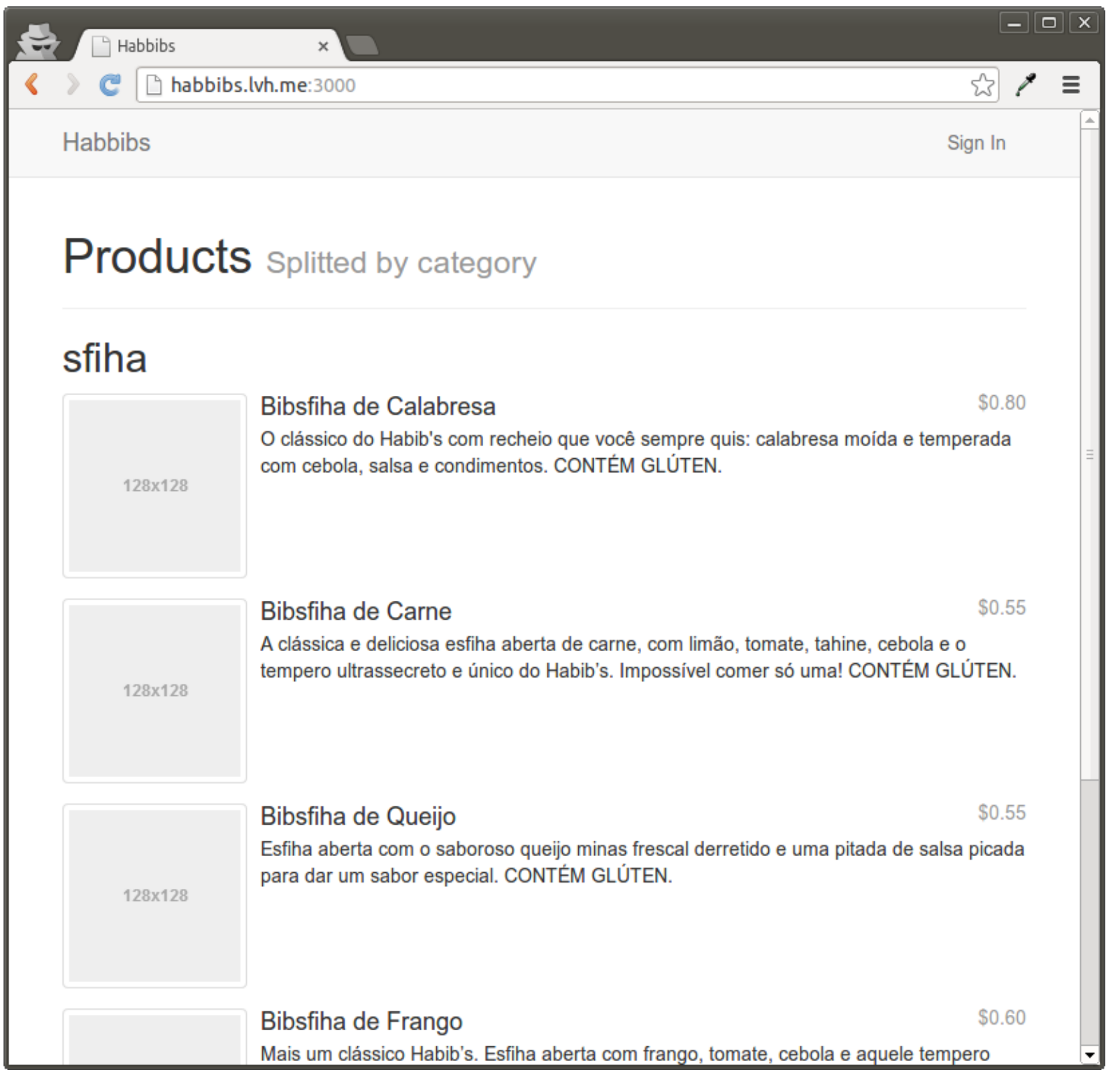

Figura 3.5: Exemplo de um tenant em um SaaS usando o mecanismo de Multitenancy

\subsection{Considerações Finais}

O provimento de um mecanismo de customização de interfaces em ambientes SaaS, objetivo principal deste trabalho, deve ser oferecido sobre uma infraestrutura Multitenancy não intrusiva que possa ser implementada em diferente plataformas as quais possam fazer uso de linguagens de programação e de frameworks de desenvolvimento Web amplamente 


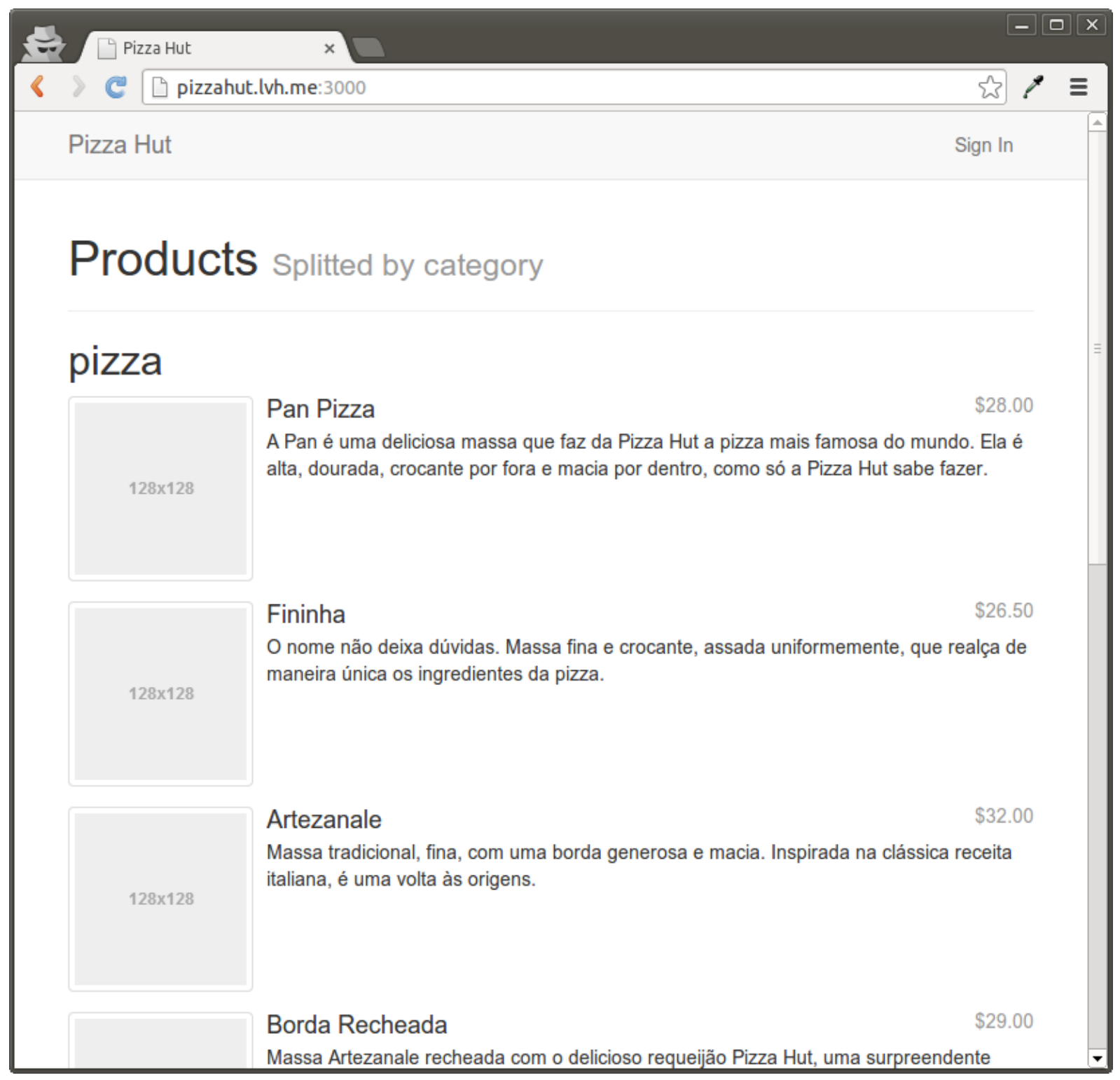

Figura 3.6: Exemplo de um segundo tenant em um SaaS usando o mecanismo de $M u l$ titenancy

utilizados atualmente. Para atender a tal condição inicial, a primeira contribuição deste trabalho é a especificação e a implementação de uma infraestrutura SaaS de referência que implementa um mecanismo de Multitenancy, chamada DORMT SaaS (Domain-based shaRed-database $\boldsymbol{M}$ ulti Tenancy SaaS), conforme detalhado neste capítulo. Essa infraestrutura foi utilizada como base para o projeto do mecanismo de customização de interfaces baseados em temas, conforme detalhado no próximo capítulo. 


\section{MHT: Multitenant Hierarchical Themes}

\subsection{Considerações Iniciais}

Com o mecanismo de referência para a implementação de sistemas SaaS Multitenant definido no Capítulo 3, DORM, foi possível dar andamento ao projeto, especificação e implementação de um mecanismo para a customização de interfaces para esse tipo de sistema. Como apresentado no Capítulo 2, o uso da arquitetura Multitenant traz inúmeros benefícios tanto para clientes quanto para provedores, mas acarreta problemas com relação a flexibilidade do sistema para atender requisitos específicos dos clientes.

Dependendo do ramo de atividade dos clientes que irão utilizar o SaaS, a possibilidade de customização da interface com o usuário pode ser um fator determinante para que um cliente contrate o serviço, ou ao menos seja um diferencial para que o cliente escolha um determinado serviço entre outros existentes no mercado. Do ponto de vista do provedor, um mecanismo que permita a customização das interfaces por tenant o aproxima de um maior grau de maturidade em SaaS, pois possibilita que a mesma aplicação sirva a um maior número de clientes apenas através de customizações e de configurações na mesma instância do sistema.

Como discutido na Capítulo 2, existem pesquisas e implementações que visam atacar esse problema em diferentes níveis. No entanto, as soluções existentes nem sempre são específicas para aplicações SaaS Multitenant ou, quando o são, não têm todo o seu mecanismo ou funcionamento descrito ou disponibilizado para ser reutilizado, pois mui- 
tas vezes esse mecanismo é tido como um diferencial comercial do provedor frente a seus concorrentes.

Este capítulo detalha a principal contribuição do trabalho: um mecanismo aberto para a customização de interfaces Web, projetado especificamente para o desenvolvimento de Software como Serviço que utilizam o padrão Multitenant ${ }^{1}$. Este mecanismo, chamado de MHT (Multitenant Hierarchical Themes) e construído tendo como base o mecanismo DORM descrito no Capítulo 3, não visa atender o requisito de customização de interfaces de todos os provedores SaaS, mas sim atender a uma grande parcela dos requisitos desses provedores e ao mesmo tempo em que serve de base para extensões e adaptações para outros contextos.

O MHT é um mecanismo para customização de interfaces Web em SaaS Multitenant baseado no padrão MVC que utiliza os conceitos de temas e de hierarquias para fornecer aos provedores de SaaS um mecanismo que os permita criar múltiplas camadas de apresentação para seu sistemas, e aplicá-las de forma independente a cada um de seus tenants, ao mesmo tempo em que permite a fácil customização de novos temas conforme as necessidades de seus clientes.

\subsection{0 mecanismo $\mathrm{MHT}$}

O MHT é construído como uma extensão do padrão MVC, conforme ilustrado na Figura 4.1, que se baseia em permitir que sejam criados múltiplas Views para um sistema através do uso de temas, que são conjuntos de templates para geração de markup HTML e assets (como imagens, folhas de estilo (CSS), arquivos javascript e textos) completamente diferentes e independentes entre si, e que esses temas possam ser associados aos tenants, de modo que quando uma requisição Web ao SaaS tenha seu tenant identificado, toda a camada de apresentação seja construída utilizando os arquivos do tema associado a ele. Além disso, esse mecanismo prove ferramentas de reuso baseados no conceito de hierarquia, para tornar a criação de variações de temas mais rápidas de implementar e fáceis de manter ao longo do tempo.

O MHT é composto pelos componentes View Resolver, Assets Resolver e I18 Resolver, que são responsáveis respectivamente pela resolução dos templates para a geração de markup HTML, para a resolução de arquivos como imagens, folhas de estilo e javascript, e para a resolução dos textos a serem exibidos na aplicação. Esses componentes utilizam as funcionalidades disponibilizadas pelos componentes do mecanismo de Multitenancy apresentado no Capítulo 3, Tenant Resolver e Data Partitioner, para possibilitar

\footnotetext{
${ }^{1}$ https://github.com/michetti/mht
} 


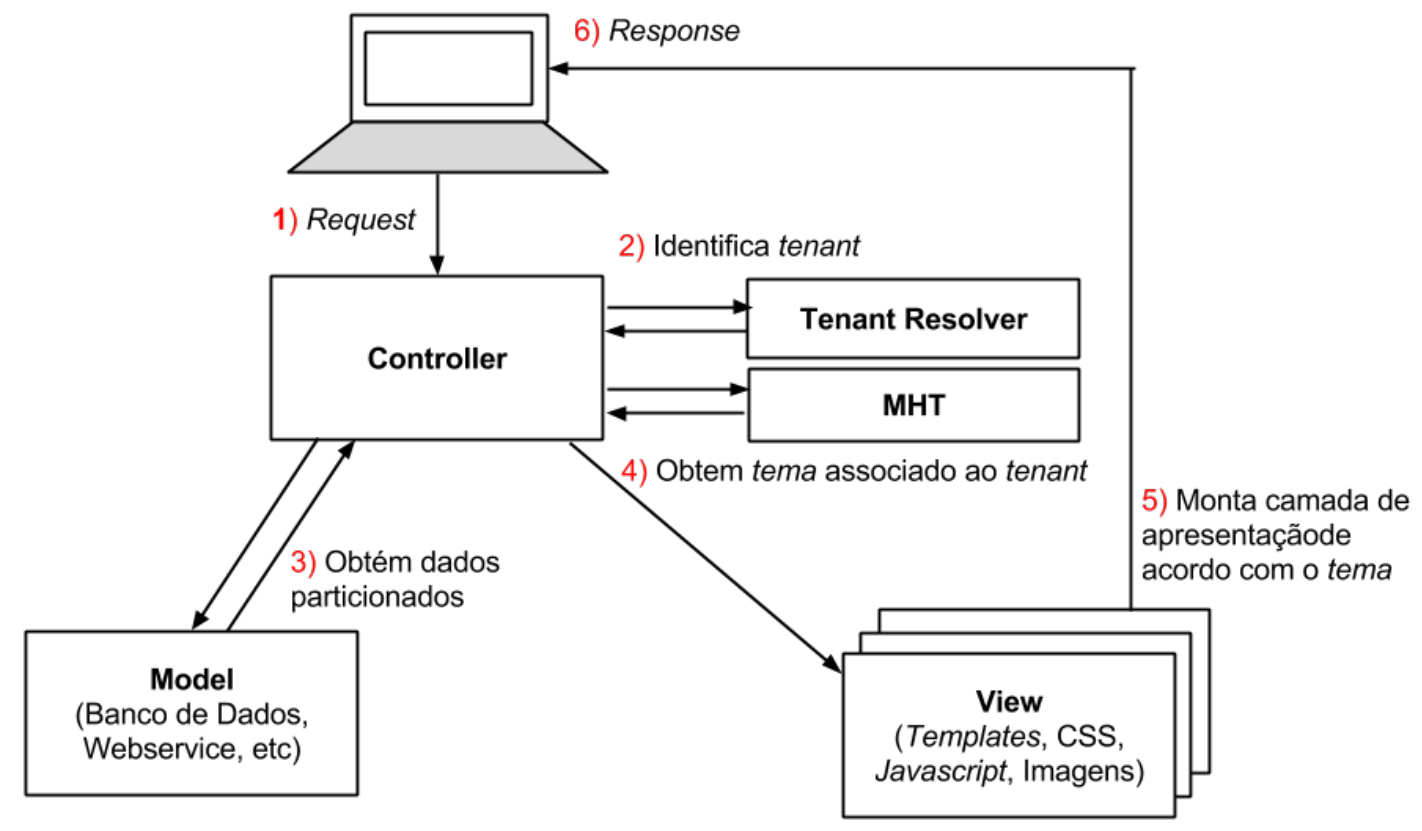

Figura 4.1: Extensão do padrão MVC no mecanismo MHT

o mapeamento de tenants para temas, e para encontrar o tema a ser usado para construir a camada de apresentação em uma determinada requisição Web.

Os temas no MHT possuem uma relação de filho para pai, que é utilizada para criar um mecanismo de hierarquia na resolução de seus templates e seus assets. Por exemplo, se um dado provedor SaaS disponibiliza os temas A e B, mas de modo que o tema B é apenas uma variação do tema A, é possível no MHT mapear o tema A como pai de B, de modo que se a resolução de um template ou assets em B falhar, a resolução passará a procurar esses arquivos no tema A. Se ainda assim a resolução desses arquivos falhar, um tema definido como padrão será utilizado para obter os arquivos. Esse mecanismo permite que os temas não precisem redefinir todos os arquivos da camada de apresentação da aplicação, agilizando a criação de variações dos temas, ao mesmo tempo que permite que esses arquivos possam ser totalmente redefinidos se necessário para criar layouts e apresentações totalmente diferentes.

É importante perceber que o uso do mecanismo de hierarquias deve ser usado com cuidado, para não prejudicar a performance do sistema e observar que mudanças em um tema pai de uma hierarquia pode acarretar mudanças em todos os seus temas filhos, se esses não sobrescreverem os arquivos modificados no tema pai. Esses pontos serão melhor detalhados nas sessões 4.2.2 e 4.4. 


\subsubsection{Temas}

No MHT os temas são pacotes que contém todo o conjunto de recursos necessário para que o sistema possa montar a camada de apresentação com o usuário em uma aplicação Web, e os metadados que os identificam. Dessa forma, um tema contém um conjunto de arquivos de template, que são usados para gerar dinamicamente os arquivos HTML que serão enviados como resposta a uma requisição Web, os assets, ou seja, arquivos de folha de estilo (CSS), imagens e textos utilizados nessas páginas, e uma representação dos dados do tema em si, como seu identificador, sua descrição, o caminho no sistema de arquivos do servidor para seus arquivos, e uma referência para um tema pai, se ele não for um tema base. A Figura 4.2 mostra uma representação gráfica do conteúdo de um tema no MHT.

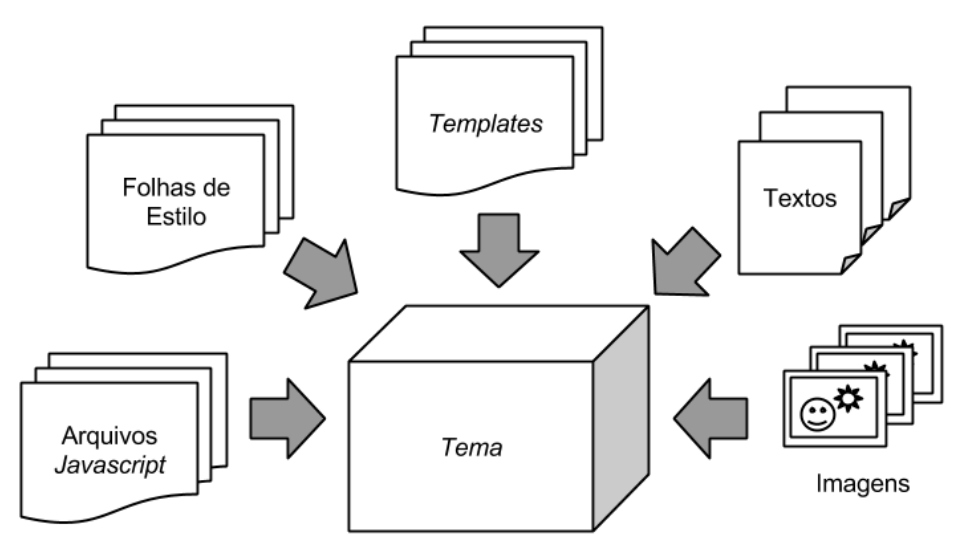

Figura 4.2: Conteúdo de um Tema MHT

A possibilidade de definir e utilizar múltiplos temas permite que um SaaS possa ter implementações totalmente distintas de interface com o usuário, permitindo aos tenants escolherem o tema que mais se aproxime de sua identidade visual, ou mesmo que temas sejam totalmente customizados para as necessidades de algum cliente específico.

O uso dos temas por si só já oferece uma grande vantagem para os provedores SaaS, mas o processo de implementação de temas com pouca variabilidade poderia trazer problemas sérios de retrabalho e manutenção ao longo do tempo. Para ajudar a combater esses problemas, a seção a seguir detalha um mecanismo de reuso através da criação de hierarquias de temas.

\subsubsection{Hierarquia de Temas}

O MHT permite a customização de interfaces por tenant através do uso de temas, mas ele também oferece um mecanismo de reuso para facilitar a criação de temas com pouca 
variabilidade e para diminuir os problemas com manutenção que poderiam ser causados se a cada variação de um tema fosse necessário replicar todos os seus arquivos.

A Figura 4.3 mostra uma hierarquia fictícia de temas construída usando o MHT, representada através de uma árvore de temas. Nessa hierarquia, existe um tema raiz, chamado de tema padrão, e um conjunto de temas bases. Nesse exemplo, os temas bases representam implementações de interface com o usuário muito diferentes entre si, sendo que não é possível um grande reaproveitamento de seus arquivos. Por exemplo, o tema $A$ poderia ser construído utilizando um framework CSS como o Twitter Bootstrap ${ }^{2}$, o tema $B$ construído utilizando um framework CSS totalmente diferente, como o Foundation ${ }^{3}$, enquanto que o tema $\mathrm{C}$ poderia ser uma implementação de interface com o usuário que utilizasse o framework Javascript Ember.js ${ }^{4}$. Já os temas como tema A.1 ou B.1, representam nesse exemplo temas com alguma variação de layout, estilo, ou mesmo da paleta de cores de seus temas base, possivelmente para atender a algum requisito específico de algum cliente do serviço.

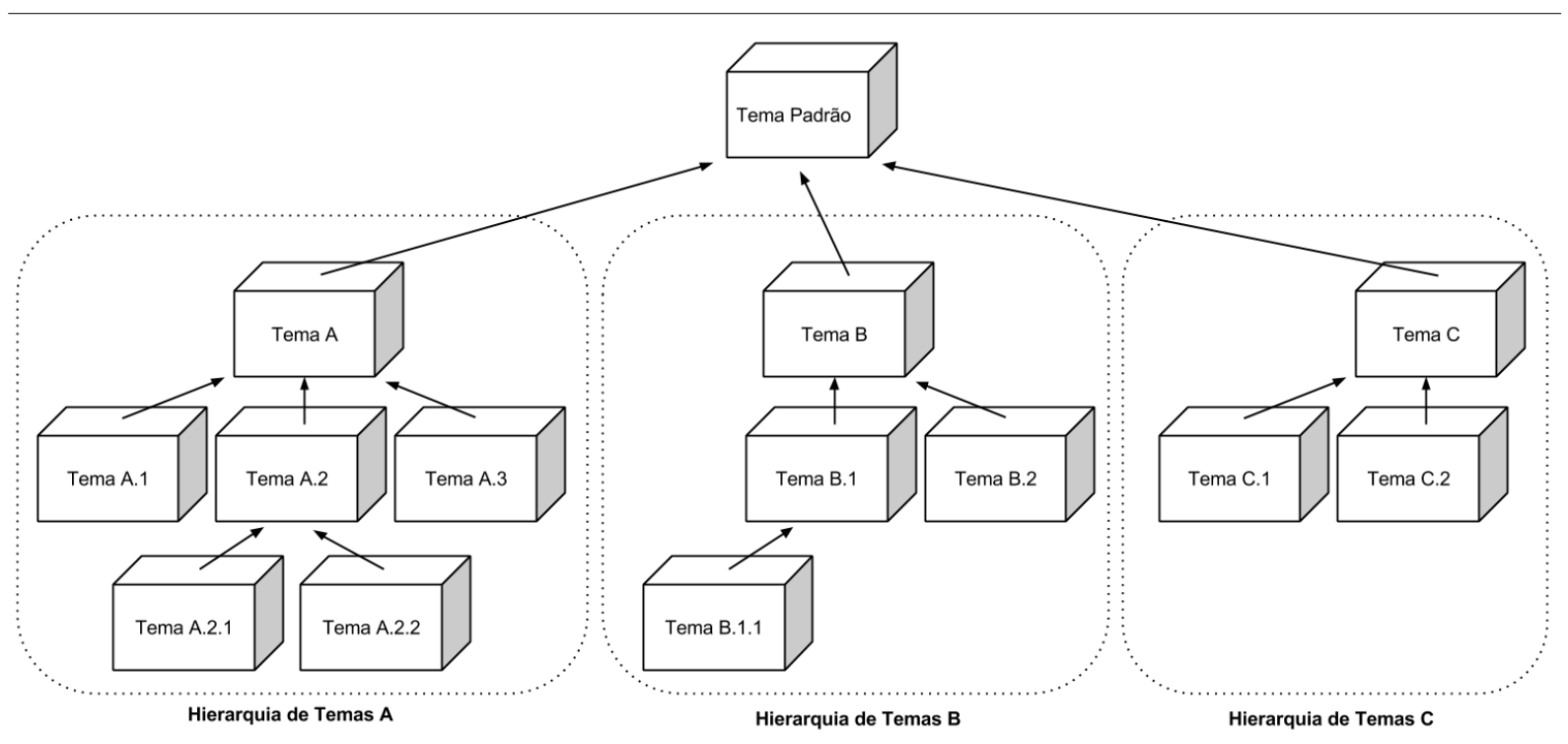

Figura 4.3: Exemplo de Hierarquia de Temas no MHT

O mecanismo de hierarquia permite que um tema filho sobrescreva um arquivo do tema pai, permitindo assim customizações nos temas, e ao mesmo tempo, garante que se um arquivo não for encontrado em um tema filho, que ele será procura recursivamente nos temas pais, evitando que todos os arquivos de um tema precisem ser replicados toda vez que uma variação de um tema for criado, evitando assim problemas de manutenção caso algum arquivo precise ser modificado.

\footnotetext{
${ }^{2}$ http://getbootstrap.com/

${ }^{3}$ http: //foundation.zurb.com/

${ }^{4}$ http://emberjs.com/
} 
A Tabela 4.1 contém uma representação dessa hierarquia de temas em uma tabela de um banco de dados relacional da forma como é utilizada na implementação de referência do MHT. A coluna id define um nome único para o tema, enquanto que a coluna parent_id, faz a ligação entre filho e pai, sendo que um tema pai pode ter múltiplos temas filhos, mas um tema filho só pode ter um tema pai. Também é importante ressaltar que o mecanismo não define um número máximo de filhos para um tema e nem uma profundidade máxima para uma hierarquia.

Tabela 4.1: Exemplo de Hierarquia de Temas no MHT

\begin{tabular}{|l|l|l|l|}
\hline id & parent_id & name & description \\
\hline theme_a & NULL & Theme A & Tema base usando Twitter Bootstrap \\
\hline theme_a_1 & theme_a & Theme A.1 & Muda layout da galeria de produtos \\
\hline theme_a_2 & theme_a & Theme A.2 & Adiciona navegação a esquerda \\
\hline theme_a_3 & theme_a & Theme A.3 & Usa uma nova paleta de cores \\
\hline theme_a_2_1 & theme_a_2 & Theme A.2.1 & Muda o estilo do mapa com o endereço \\
\hline theme_a_2_2 & theme_a_2 & Theme A.2.2 & $\begin{array}{l}\text { Muda para um menu de navegação a } \\
\text { direita }\end{array}$ \\
\hline theme_b & NULL & Theme B & Tema base usando Foundation CSS \\
\hline theme_b_1 & theme_b & Theme B.1 & Página específica do cliente XPTO \\
\hline theme_b_2 & theme_b & Theme B.2 & Customização para cliente ABCD \\
\hline theme_b_2_1 & theme_b_2 & Theme B.2.1 & Muda paleta de cores \\
\hline theme_c & NULL & Theme C & $\begin{array}{l}\text { Implementação em Javascript com Em- } \\
\text { ber.js }\end{array}$ \\
\hline theme_c_1 & theme_c & Theme C.1 & Muda layout base do tema \\
\hline theme_c_2 & theme_c & Theme C.2 & Muda layout e paleta de cores \\
\hline
\end{tabular}

A implementação de referência do MHT utiliza o conceito de padronização ao invés de configuração para definir como os arquivos reais dos temas devem ser armazenados no sistema de arquivos do servidor. Ou seja, ao invés de definir um caminho para os arquivos do tema no sistema arquivos na tabela de temas, a implementação de referência utiliza apenas uma configuração para o diretório raiz onde todos os temas serão armazenados no servidor, e define um estrutura de diretórios padrão para cada um dos temas. Essa estrutura de diretórios pode ser visualizada na Figura 4.4.

\subsubsection{Componentes do MHT}

As sessões a seguir irão detalhar o funcionamento dos componentes que compõem o mecanismo MHT, através de uma descrição de suas funções, do uso de diagramas e listagens de código de sua implementação de referência e de suas interações com os componentes do mecanismo de Multitenancy. 


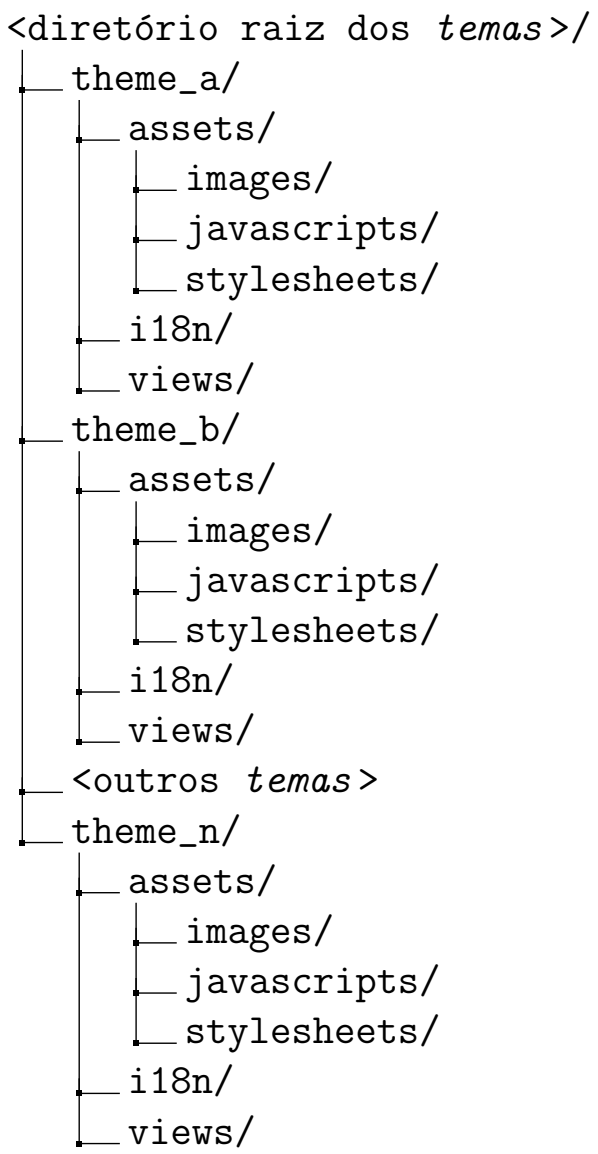

Figura 4.4: Estrutura de diretórios para armazenar os arquivos dos Temas no MHT

\subsubsection{Theme Resolver}

O componente Theme Resolver é responsável por retornar a entidade que representa um tema no MHT a partir de um tenant_id. Ele é usado diretamente por praticamente todos os componentes do MHT, que irão inicialmente interagir com o componente Tenant Resolver do mecanismo de Multitenancy para obter o tenant_id.

\subsubsection{View Resolver}

O componente View Resolver é responsável por encontrar e retornar os arquivos que serão que contém, ou que serão usados para gerar dinamicamente, a markup HTML da camada de apresentação do tema associado a requisição Web corrente. Este componente recebe do Controller um identificador da View que será renderizada, e então interage com o componente Tenant Resolver, para obter o tenant associado a requisição Web corrente, e por fim com o componente Theme Resolver para obter o tema associado ao tenant encontrado. 
Com o tenant encontrado, o componente busca na estrutura de diretórios padrão do MHT o arquivo de template referente ao identificador da view passado como parâmetro pelo Controller. Se o arquivo for encontrado diretamente na estrutura de diretórios do tema, esse arquivo é retornado para o Controller que usa os dados particionados do tenant corrente para renderizar a markup HTML que será enviada como response. Se o arquivo não for encontrado, o componente busca recursivamente na hierarquia de temas o arquivo nos pais do tema corrente, retornando o arquivo assim que for encontrado. Se o arquivo não for encontrado em nenhum dos temas pais, ele será procurado no tema padrão da aplicação.

É importante notar que o arquivo retornado por esse componente pode ser tanto um arquivo estático quanto um arquivo dinâmico, como arquivos JSP em Java EE ou ERB em Ruby on Rails. A Figura 4.5 mostra um fluxograma com esse mecanismo no MHT.

A Listagem 4.1 mostra a implementação de um View Resolver no framework Ruby on Rails. Nesse framework os controllers que terão suas views customizáveis por tenant, devem incluir o método definido na listagem como um filtro. Esse método obtém o tema a partir do tenant, e adiciona o caminho de todos os temas pais do tema atual a uma lista, que é usada pelo framework Ruby on Rails para encontrar os tempaltes para a renderização da view.

Listagem 4.1: Implementação de View Resolver como um filtro em Ruby on Rails

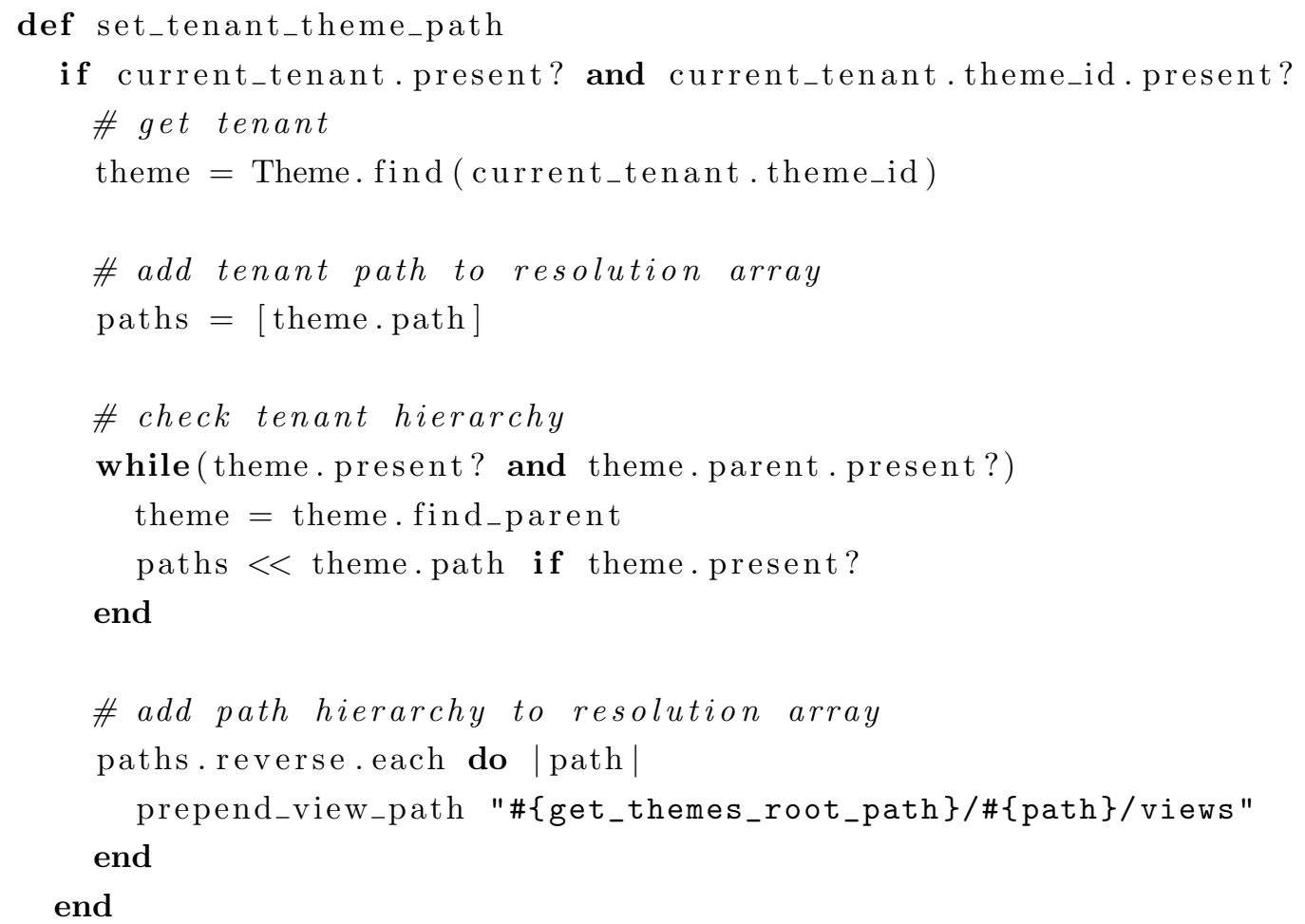




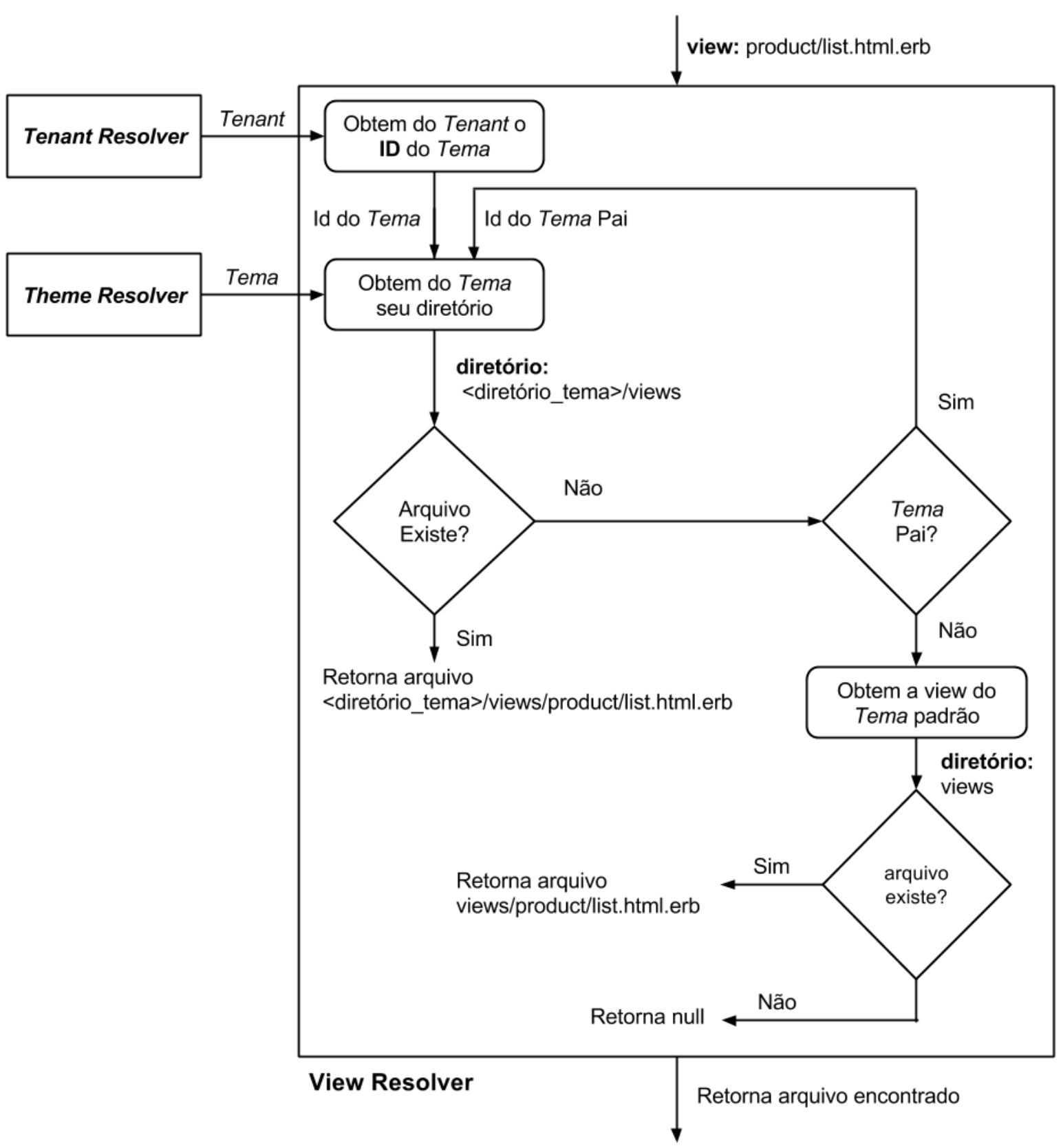

Figura 4.5: Resolução de Views com $M H T$

\subsubsection{Assets Resolver}

O componente Assets Resolver tem um comportamento bastante similar ao componente View Resolver, mas ao invés de retornar arquivos responsáveis pelo markup HTML da camada de apresentação, ele é responsável por retornar arquivos como imagens, folhas de estilo (CSS), arquivos javascript, ou qualquer outro arquivo referenciado pelos arquivos de markup retornados pelo componente View Resolver. A Figura 4.6 mostra um fluxograma do funcionamento desse componente. 


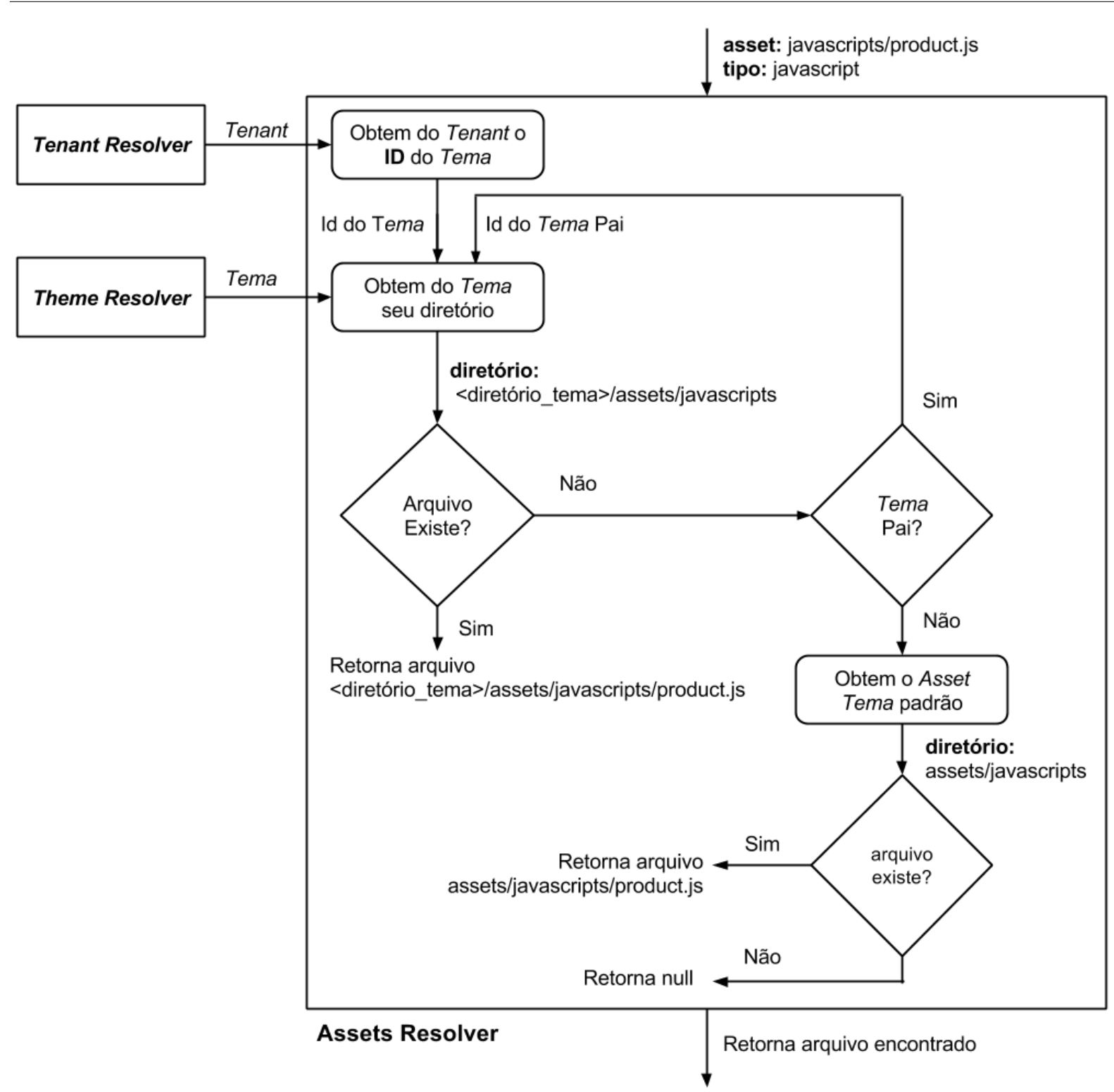

Figura 4.6: Resolução de Assets com $M H T$

Como pode ser visto no fluxograma, esse componente também procura pelos arquivos recursivamente nos temas pais, caso ele não seja encontrado no tema associado diretamente ao tenant. Também é importante ressaltar que os assets também podem ser dinâmicos, como por exemplo arquivos do tipo Dynamic Stylesheets implementadas em frameworks como SCSS ${ }^{5}$ e $\mathrm{LESS}^{6}$ para gerar CSS, ou Cofeescript ${ }^{7}$ para gerar Javascript, todos bastante utilizados em frameworks como Ruby on Rails.

A Listagem 4.2 mostra como um este componente pode ser facilmente implementado no framework Ruby on Rails. Nesse framework, os assets são procurados em uma lista de

\footnotetext{
${ }^{5}$ http: //sass-lang.com/

${ }^{6}$ http://lesscss.org/

${ }^{7}$ http://coffeescript.org/
} 
diretórios configurável, de modo que basta utilizar basta adicionar todos os subdiretórios de assets do diretório principal dos temas a essa lista, e então referenciá-los nos arquivos de template do tema.

Listagem 4.2: Implementação do componente Assets Resolver em Ruby on Rails

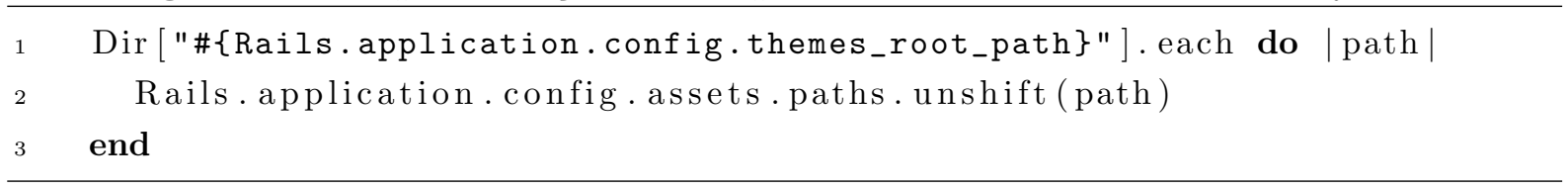

\subsubsection{I18n Resolver}

O componente I18n Resolver é responsável pela obtenção de textos customizados dos temas e também pela internacionalização desses textos. A necessidade de internacionalização de textos é bastante comum em aplicações Web, sendo que a maioria dos frameworks Web oferecem essa funcionalidade, muitas vezes abreviada como I18N (do inglês, internationalization). Esse mecanismo é geralmente implementado através da substituição dos textos nos templates de interface por identificadores que são posteriormente substituídos pelo texto propriamente dito, já no idioma do usuário que originou a requisição Web. São criados então diversos arquivos que mapeiam os identificadores para os textos reais que serão usados na interface da aplicação, sendo que geralmente cada arquivo contém o mapeamento desses identificadores para um determinado idioma.

No MHT, esse mecanismo é estendido para permitir que cada tema defina seu próprio conjunto de arquivos de internacionalização, tornando possível aos temas mudarem os textos exibidos na interface com o usuário. Veja que esse componente, ao contrário dos demais no MHT, não são hierárquicos, ou seja, se o tema contém arquivos de internacionalização, eles serão usados por completo, e não os do pai, e se o tema não definir esses arquivos, os valores do tema padrão serão utilizados. Ou seja, se um tema desejar mudar algum texto na aplicação, ele deve fazer a cópia de todos os arquivos de tradução do tema padrão ou de seu tema pai. Essa diferença visa impedir problemas como mudança de afirmações ou instruções nos textos dos temas, que podem acarretar problemas ao provedor do serviço. O fluxograma do funcionamento deste componente pode ser visto na Figura 4.7 .

A implementação de referência deste componente em Ruby on Rails depende da definição de um backend para especificar o carregamento e obtenção dos arquivos de internacionalização de dentro dos diretórios dos temas, como pode ser visto na Listagem 4.3 e da configuração do framework para utilizar esse novo backend quando um identificador precisar ser mapeado para o texto internacionalizado, como pode ser visto na Listagem 4.4.

Listagem 4.3: Implementação do componente I18N Resolver em Ruby on Rails 


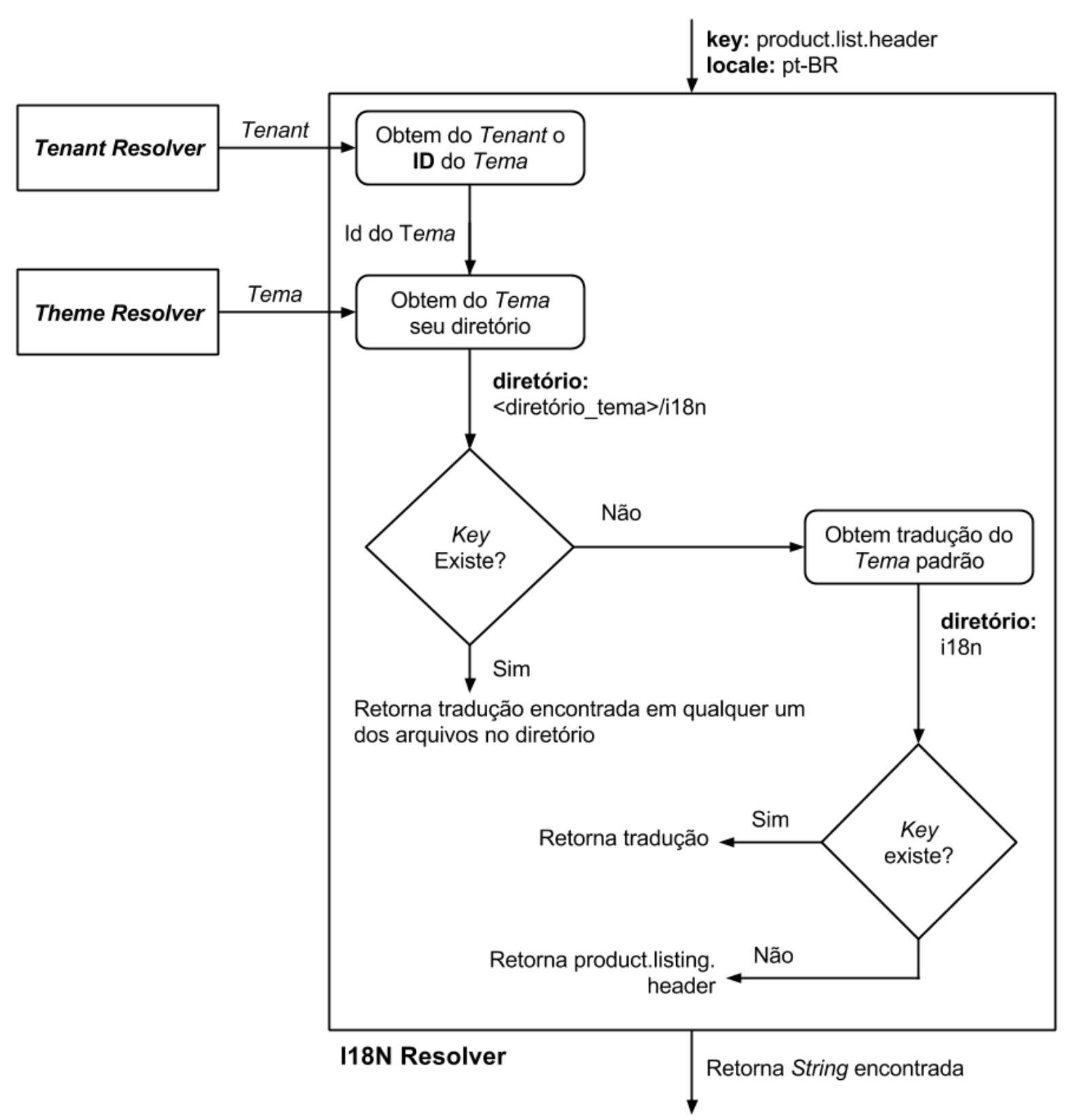

Figura 4.7: Internacionalização de textos com $M H T$

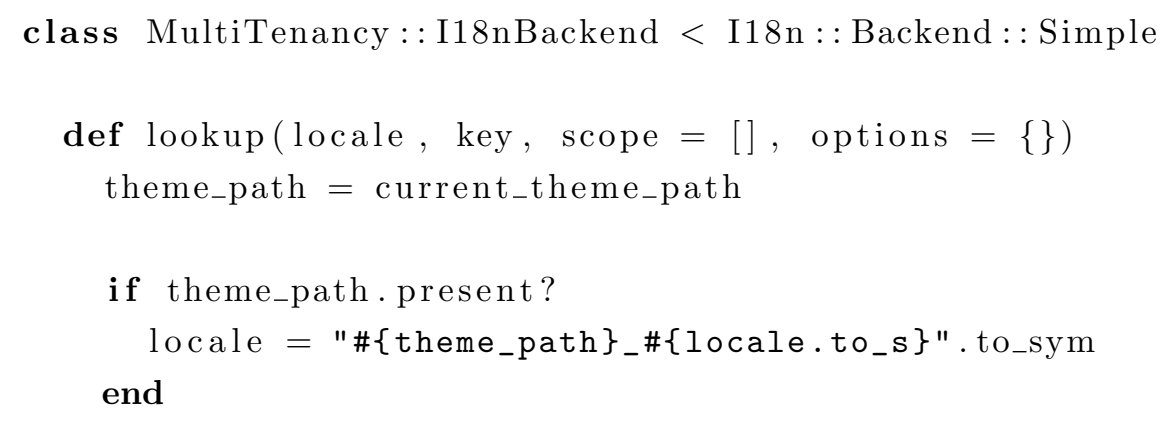


init_translations unless initialized?

keys $=$ I18n.normalize_keys (locale, key, scope, options [: separator])

keys.inject(translations) do |result, _key $\mid$

-key $=$ _key.to_sym

return nil unless result.is_a?(Hash) \&\& result.has_key?(_key)

result $=$ result $\left[{ }_{-}\right.$key $]$

if result. is _a? (Symbol)

result $=$ resolve(locale, _key, result, options.merge $($ : scope $\Rightarrow$ nil $)$

)

end

result

end

end

def load_file(filename)

type $=$ File $\cdot$ extname $($ filename $) \cdot \operatorname{tr}\left({ }^{\prime} \cdot{ }^{\prime},{ }^{\prime}, '\right) \cdot$ downcase

unless respond_to?(:"load_\#\{type $\} "$, true)

raise UnknownFileType.new(type, filename)

end

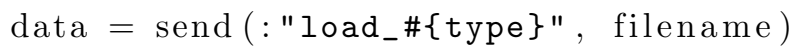

unless data.is_a?(Hash)

raise InvalidLocaleData.new(

filename,

'expects it to return a hash, but does not'

)

end

data.each do |locale, d |

if filename $=^{\sim} / \wedge /$ opt $\backslash /$ themes $\backslash /(. *) \backslash / \mathrm{i} 18 \mathrm{n} \backslash / . * \backslash \cdot \mathrm{yml} \$ /$

theme_path $=\$ 1$

locale $=" \#\{\text { theme_path }\}_{-} \#\{$ locale.to_s ".to_sym

end

store_translations (locale, $\mathrm{d} \|\{\}$ )

end

end

end 
Listagem 4.4: Configuração do componente I18N Resolver em Ruby on Rails

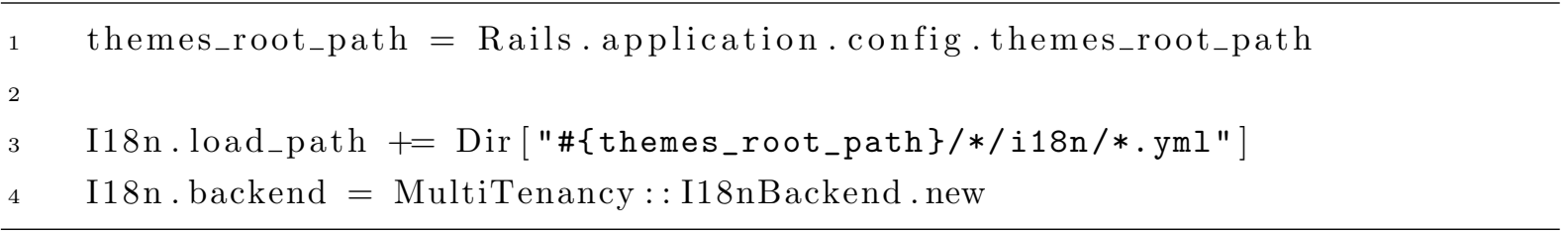

\subsection{Mecanismo Proposto em Uso}

Para mostrar o mecanismo MHT em uso, o mesmo SaaS para a criação de lojas virtuais para restaurantes criado para exemplificar o uso do mecanismo de Multitenancy apresentado no Capítulo 3, foi utilizado. A Figura 4.8 mostra a página inicial do tenant identificado pelo subdomínio habbibs, exibindo apenas os dados desse tenant e utilizando um tema baseado no framework CSS Twitter Bootstrap, enquanto que a Figura 4.9 mostra a mesma página inicial nesse mesmo sistema, mas para um segundo tenant, identificado pelo subdomínio pizzahut, utilizando um outro tema, baseado no framework Foundation CSS.

Comparando as Figuras 4.8 e 4.9 com as Figuras 3.5 e 3.6, é possível notar o uso de todos os componentes do mecanismo MHT, como o uso de diferentes temas para cada um dos tenants (Theme Resolver), como a mudança na estrutura das páginas (View Resolver), na mudança nas folhas de estilo (CSS) e componentes Javascript (Assets Resolver), e na mudança em textos estáticos da página I18N Resolver, como pode ser visto no título principal das páginas.

A Figura fig:ScreenshotMht3 mostra o uso do mecanismo de reuso e hierarquias de temas do MHT, com um tema bastante simples, que tem como pai o tema utilizado na Figura fig:ScreenshotMht1, e que apenas remove alguns elementos da estrutura das views (remove o componente carousel), a mudança nas cores do fundo da página e das cores de fontes utilizadas em alguns cabeçalhos, além da mudança no texto estático.

\subsection{Boas práticas no uso do MHT}

Algumas boas práticas podem ser observadas ao utilizar o MHT, no que se refere a forma como o mecanismo de hierarquias deve ser utilizado, como os temas podem fazer uso de sistemas de controle de versão para facilitar seu desenvolvimento e manutenção, e como os Controllers da aplicação podem ser construídos para possibilitar uma maior variabilidade dos temas. 


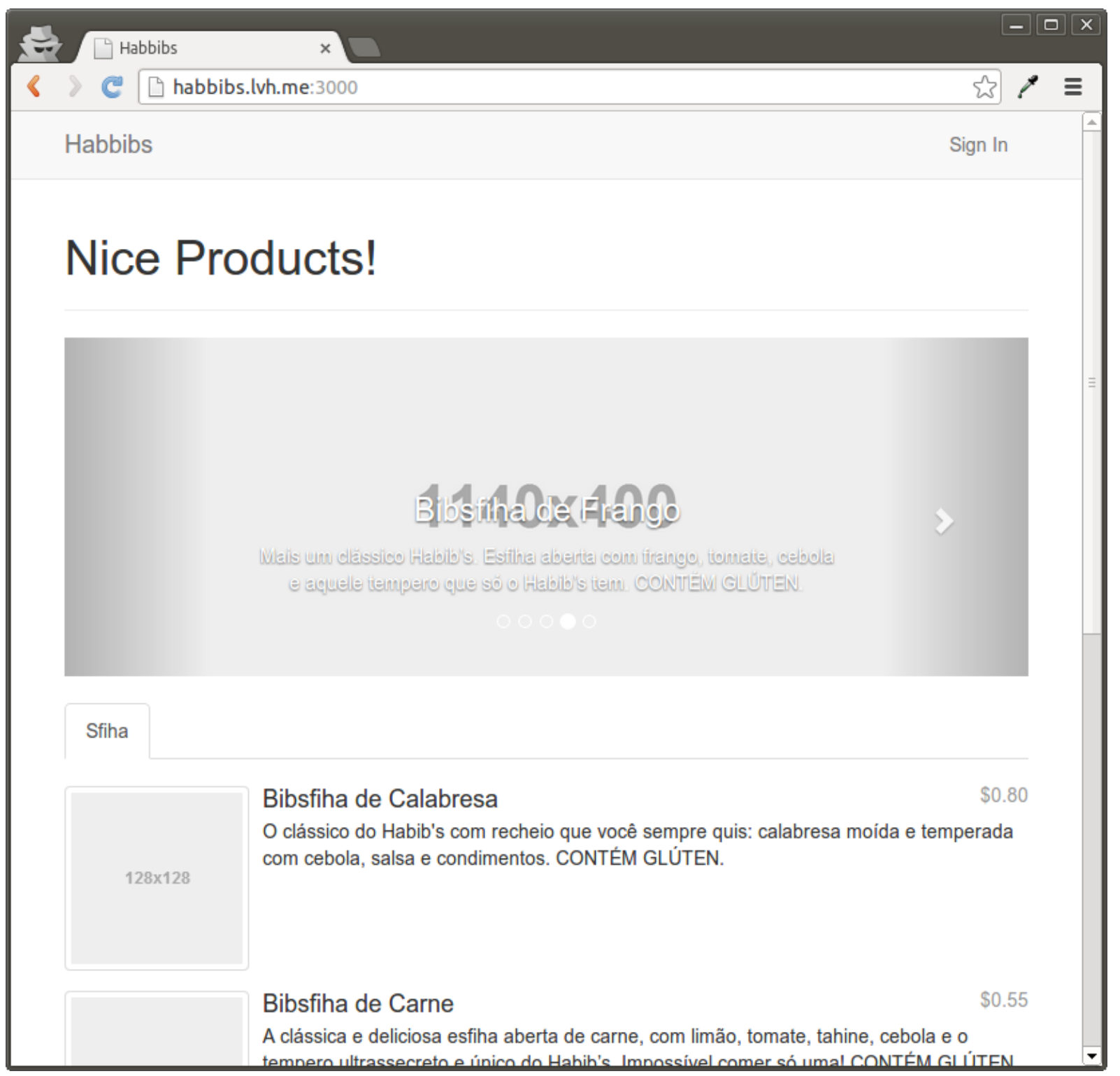

Figura 4.8: Exemplo de um tenant usando um tema MHT

O mecanismo de hierarquias de temas permite que variações não muito complexas de temas existentes possam ser implementadas rapidamente, hierarquias muito profundas podem tornar as tarefas de resolução de templates e assets muito demoradas, pois se apenas alguns arquivos forem modificados em um determinado tema, a resolução de todos os arquivos não redefinidos será feita através da procura recursiva desses arquivos nos temas pais.

Outro ponto importante a ser levado em consideração é a forma como o código em si dos temas pode ser gerenciada ao longo do tempo. Uma forma interessante de fazer 


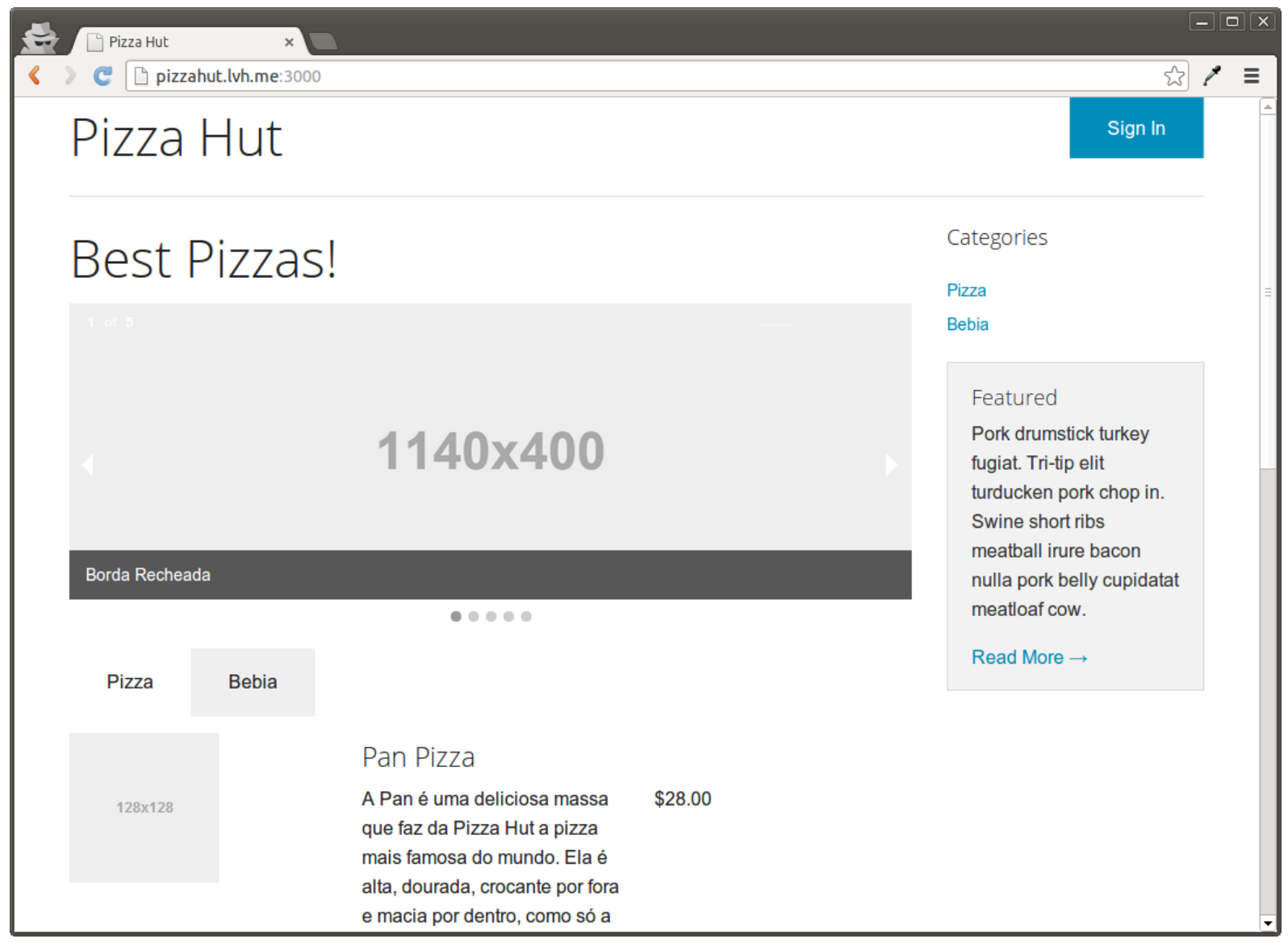

Figura 4.9: Exemplo de um segundo tenant usando um outro tema MHT

esse controle, é usar ferramentas de controle de versão, como o Git ${ }^{8}$ ou Subversion ${ }^{9}$. Nesses sistemas, seria possível criar um repositório para cada tema base, e controlar suas customizações através de branches, tornando mais fácil tarefas como comparações de código, ou merge em arquivos que foram customizados, mas que tiveram os arquivos originais atualizados.

Por fim, para permitir uma maior variabilidade na construção dos temas, é interessante construir a camada de Controllers da aplicação como uma API que é capaz de retornar os dados em diferentes formatos, como HTML, JSON ou XML. Muitos frameworks Web como Ruby on Rails oferecem suporte para isso, utilizando o modelo REST como padrão para a definição de seus Controllers e oferecendo ferramentas para que os métodos de seus Controllers possam retornar dados em diferentes formatos. A construção dos Controllers como uma API capaz de retornar dados tanto em HTML como JSON, possibilitaria a construção tanto de temas que renderizam a camada de apresentação nos servidor, quanto

\footnotetext{
${ }^{8}$ http://git-scm.com/

${ }^{9}$ http://subversion.apache.org/
} 


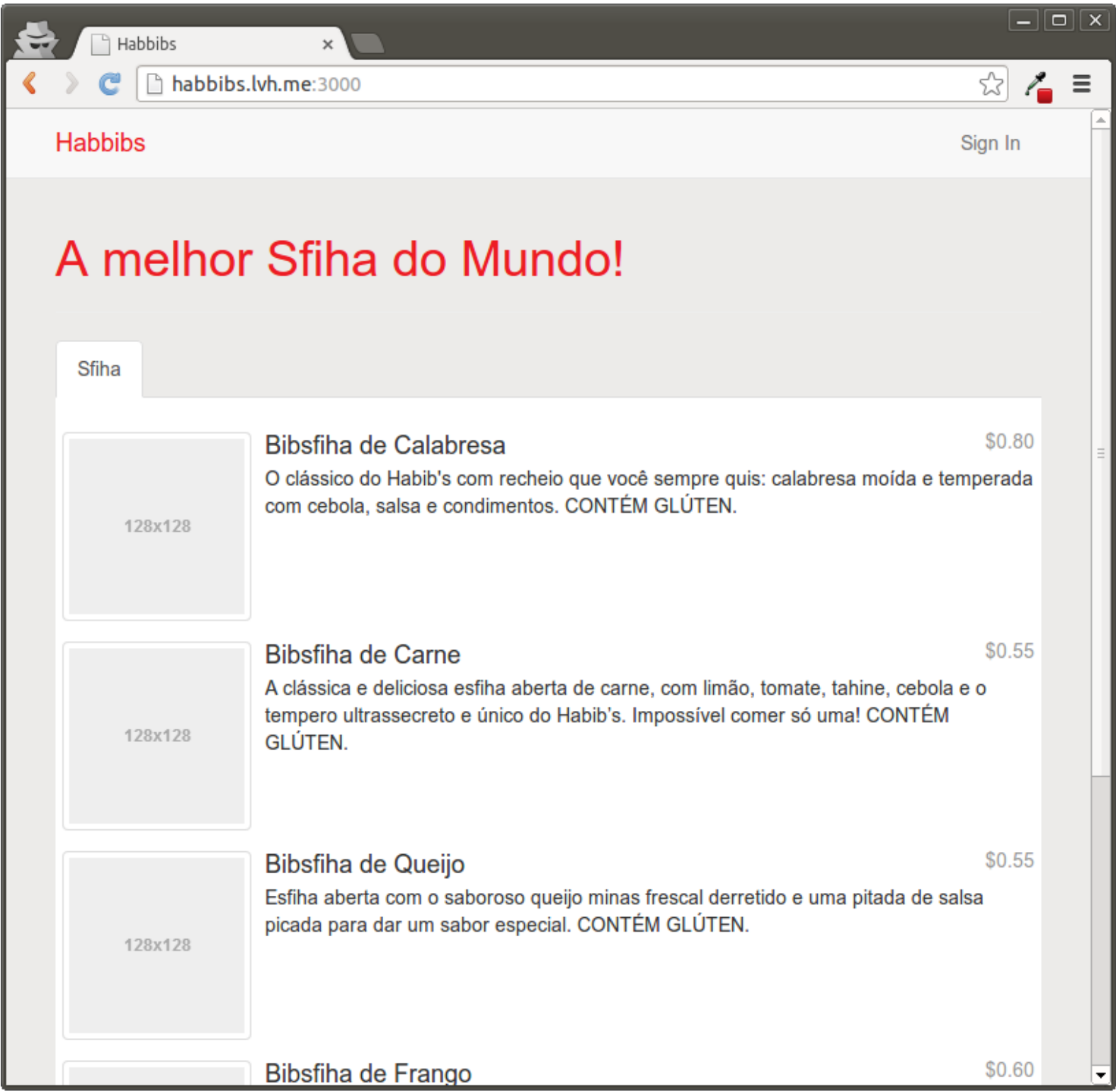

Figura 4.10: Exemplo de um tema usando o mecanismo de hierarquias do MHT

temas que utilizam Javascript para renderizar a camada de apresentação com usuário no navegador do usuário, utilizando os dados JSON retornados do servidor.

\subsection{MHT: Pontos Fortes}

O MHT tem como principais vantagens a possibilidade de provedores SaaS utilizarem temas para criar múltiplas interfaces com o usuário para seus serviços e utilizar temas diferentes para cada um de seus clientes. Além disso, o mecanismo de hierarquia permite que sejam criadas pequenas variações de temas existentes com pouco trabalho, facilitando a manutenção e evolução dos temas. 
As implementações de referencia em Ruby on Rails, disponibilizadas como Software Livre e encapsuladas em componentes reutilizáveis e não intrusivos, permite que implementações em outras linguagens e frameworks possam ser mais facilmente desenvolvidas e que provedores SaaS que trabalham com Ruby on Rails possam se utilizar e se beneficiar desses mecanismos rapidamente.

\subsection{MHT: Pontos Fracos}

O principal ponto fraco do MHT é não permitir que os próprios tenants criem seus temas ou configurem os temas existentes. Ou seja, apenas o provedor do serviço pode desenvolver e customizar temas, sendo que atualmente o mais próximo de permitir que um tema seja desenvolvido por um terceiro, seria disponibilizar o código fonto de um tema existente para ele, mas que não seria muito prático para ser customizado, pois o terceiro não teria a principio como testar suas alterações, já que não tem acesso ao ambiente da aplicação e seus dados.

A possibilidade de permitir que terceiros possam desenvolver temas foi inicialmente pensada para o MHT, mas ao longo do desenvolvimento deste trabalho, o autor percebeu os problemas de segurança e performance que essa funcionalidade poderia trazer ao sistema, principalmente em um ambiente totalmente compartilhado como no caso de SaaS Multitenant.

Esse mecanismo só seria possível de forma prática, se o código escrito por terceiros fosse executado em um sandbox ${ }^{10}$, especialmente criado para garantir que esse código não possa acessar dados de outros tenants e com restrições ao seu tempo de execução. Dessa forma, a complexidade desse mecanismo impediu que ele fosse desenvolvido no escopo deste trabalho, mas pode ser pensado como um trabalho futuro para expandir o mecanismo MHT.

\subsection{Considerações Finais}

A pesquisa teve como motivação um dos principais problemas de customização no modelo SaaS: a customização de interfaces Web em sistemas SaaS Multitenant. Assim, o trabalho teve como objetivo propor uma solução na forma de um mecanismo reutilizável e não intrusivo. O mecanismo proposto neste capítulo, baseado no padrão MVC, foi denominado MHT (Multitenant Hierarchical Themes) por explorar os conceitos de temas e de hierarquias.

\footnotetext{
${ }^{10}$ http://en.wikipedia.org/wiki/Sandbox_(computer_security)
} 


\section{CAPÍTULO 4. MHT: MULTITENANT HIERARCHICAL THEMES}

No próximo capítulo são sumarizadas as contribuições do trabalho e discutidas oportunidades de trabalhos futuros. 



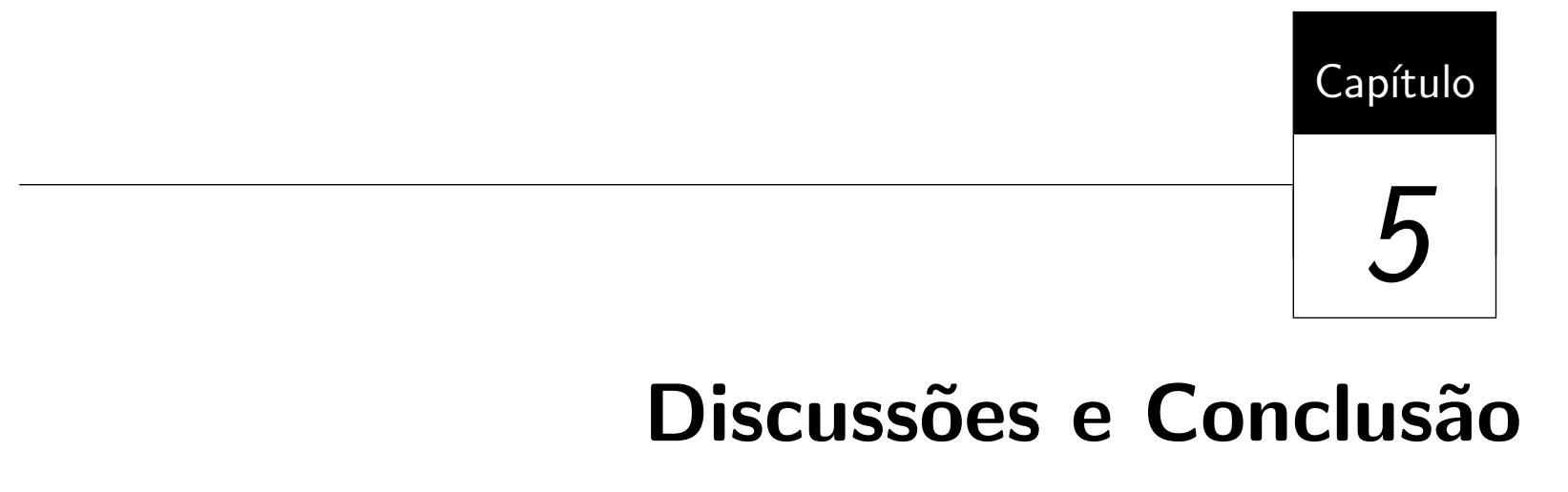

\subsection{Considerações Iniciais}

SaaS é um modelo de distribuição de software onde provedores oferecem software através da internet, os quais são desenvolvidos e mantidos por esses próprios provedores, para clientes que pagam uma taxa para utilizá-los. A possibilidade de distribuir seu software para o mundo todo através da internet, sem depender de terceiros para a distribuição e venda de seus sistemas, aliado ao fato de os provedores poderem fazer escolhas com relação a arquitetura, desenvolvimento e operação de seus sistema visando diminuir complexidade e custos, possibilita a esses provedores utilizarem novos modelos de negócio para conseguirem lucro. Muitos desses modelos de negócio são baseados em economia de escala, de modo que o lucro é gerado pelo grande número de clientes do serviço, mesmo que o custo para utilizá-lo sela relativamente baixo.

Nesse contexto, o padrão Multitenant é uma das principais ferramentas para tornar essa modelo viável, possibilitando aos provedores SaaS atingirem a escala de usuários necessária sem acarretar em grandes aumentos nos custos com a operação do serviço. No entanto, o uso desse padrão acarreta em novos desafios de desenvolvimento, muitos relacionados à flexibilidade em atender os requisitos específicos de cada cliente na customização de processos, de fluxos e regras de negócio, e de interfaces com o usuário.

Especificamente no problema de customização de interfaces, o mecanismo MHT apresentado nesta dissertação visa criar uma alternativa não intrusiva para a customização de 
interfaces Web, especifico para o contexto de Software como Serviço que utilizam Multitenancy, que pode ser implementado nas principais linguagens de programação e frameworks de desenvolvimento utilizados no estado da prática, e que seja flexível o suficiente para atender a maioria dos requisitos específicos de cada cliente de sistemas SaaS.

Retomando a Tabela 2.1 apresentada no Capítulo 2, é possível comparar a combinação dos mecanismos DORM e MHT com os trabalhos existentes e com o mecanismo ideal para a customização de interfaces, conforme apresentado na tabela 5.1

Tabela 5.1: Comparativo com Trabalhos Relacionados

\begin{tabular}{|l|l|l|l|l|l|}
\hline Quem & Tecnologia & Simples & Complexas & Terceiros & Aberto \\
\hline Kitano el al. (2010) & XPath & SIM & NÃO & NÃO & $?$ \\
\hline Li et al. (2011) & Java Portlets & SIM & NÃO & NÃO & $?$ \\
\hline Yao et al. (2011) & Java Portlets & SIM & NÃO & NÃO & $?$ \\
\hline Chae et al. (2003) & Redes Petri + XSLT & SIM & NÃO & NÃO & $?$ \\
\hline Wei et al. (2010) & XML + XSLT & SIM & NÃO & NÃO & $?$ \\
\hline Shopify & Temas & SIM & SIM & SIM & NÃO \\
\hline DORM + MHT & Temas Hierárquicos & SIM & SIM & NÃO & SIM \\
\hline$\ldots$ & $?$ & SIM & SIM & SIM & SIM \\
\hline
\end{tabular}

\subsection{Oportunidades para Trabalhos Futuros}

Este trabalho teve como principal contribuição a especificação e desenvolvimento do mecanismo MHT, mas para possibilitar o seu desenvolvimento, também foi necessário a especificação de mecanismo DORMT para o desenvolvimento de aplicações baseadas em Multitenancy. Desse modo, os trabalhos futuros apresentados neste capítulo serão referentes a essas duas contribuições.

\subsubsection{Trabalhos futuros em Multitenancy}

O mecanismo para a criação de aplicações Multitenant (DORMT) especificado neste trabalho foi desenvolvido para servir como base padrão para a criação do mecanismo MHT. No entanto, esse mecanismo poderia ser utilizado como base para trabalhos futuros focados em flexibilizar outras partes importantes de sistemas Multitenant, como a criação de mecanismos para a customização dos processos e regras de negócio por tenant, requisitos comuns a diversos tipos de aplicação. Esses mecanismos, embora complexos, seriam bastante úteis para provedores SaaS, e poderiam ser usados em conjunto, inclusive com o 
mecanismo MHT, para construir sistemas SaaS altamente customizáveis ao mesmo tempo que facilitariam a manutenção e operação desses sistemas.

\subsubsection{Trabalhos futuros em Customização de Interfaces}

Diversas melhorias poderiam ser aplicadas ao MHT, mas uma das mais importantes seria possibilitar que os próprios tenants pudessem customizar os temas que escolherem usar, ou mesmo possibilitar que eles mesmos ou terceiros possam criar novos temas.

A customização dos temas poderia envolver desde a possibilidade de edição completa das folhas de estilo (CSS), ou a adição de configurações que permitissem a definição de alguns atributos, como cores de fundo, mudança nas fontes, entre outros. Para ser mais efetivo, esse mecanismo poderia ser implementado diretamente no serviço, de modo que o cliente pudesse fazer as mudanças através de interfaces Web administrativas e visualizar as mudanças feitas diretamente no serviço em execução. Esse mecanismo de customização aumentaria a variabilidade nos temas, permitindo diferenciações mais simples no estilo e layout, mas também mais fáceis de serem operadas por usuários não técnicos.

Já a possibilidade criação de temas completos por terceiros é mais complexa, e exigiria que o usuário tenha conhecimentos de desenvolvimento Web ou de web design, mas possibilitaria mudanças muito mais profundas no estilo e layout da interface com o usuário. Esse mecanismo envolveria a pesquisa de formas de impedir que os arquivos que compõem esses temas executem código malicioso tanto no servidor quanto no navegador dos usuários.

Por código malicioso, deve-se entender código que possa modificar, apagar ou acessar dados não permitidos no servidor, ou mesmo código que use muitos recursos computacionais do servidor, uma vez que isso afetaria todos os demais tenants, e poderia ser usado para facilitar ataques de DOS (Denial of Service) ${ }^{1}$, por exemplo, criando tenants falsos e aplicando temas que utilizam muitos recursos computacionais, um usuário malicioso poderia, com um número relativamente pequeno de servidores, gerar um grande número de requisições a páginas desses tenans, de modo a consumir tantos recursos computacionais que impediriam o serviço de responder requisições válidas de outros clientes. Embora seja bastante complexa, existem implementações abertas que poderiam ser usadas como base para a implementação desse mecanismo, como o Liquid ${ }^{2}$, que poderiam ser integrados ao MHT. Tal mecanismo também se beneficiaria de editores online, assim como o proposto no mecanismo de customização dos temas, além do mecanismo de reuso baseado em hierarquia de temas disponível no MHT.

\footnotetext{
${ }^{1}$ http://en.wikipedia.org/wiki/Denial-of-service_attack

${ }^{2}$ https://github.com/Shopify/liquid
} 
Ainda no mecanismo de criação de temas por terceiros, o trabalho poderia analisar a criação de marketplaces que permitissem a esses terceiros comercializar seus temas para os tenants do serviço, assim como é feito em marketplaces de temas já estabelecidos, como os dos sistemas Shopify, Wordpress, Magento, entre outros, e como o provedor do serviço poderia se beneficiar financeiramente da criação desse mercado, por exemplo, cobrando uma porcentagem na venda de cada tema.

Um trabalho futuro não relacionado a extensão ou evolução do mecanismo MHT poderia ser baseado na avaliação do uso desse mecanismo no mundo real, como o estudo do uso desse mecanismo por algum provedor SaaS brasileiro, que tenha a customização de interfaces como um requisito importante.

\subsection{Considerações Finais}

Este trabalho de mestrado teve como resultado a criação do mecanismo DORMT para o desenvolvimento não intrusivo de aplicações Multitenant e do mecanismo MHT, criado para flexibilizar a customização de interfaces Web em sistemas SaaS Multitenant. Este trabalho gerou publicações em um importante evento acadêmico e em uma revista de ampla circulação entre empresas de desenvolvimento de software. Além disso, foram disponibilizadas implementações dos mecanismos propostos em diferentes linguagens de programação e frameworks usados amplamente nos dias de hoje, podendo ser utilizadas diretamente por empresas que queiram desenvolver sistemas SaaS ou servir como referencia na implementação desses mecanismos em outras linguagens de programação.

Dessa forma, é esperado que este trabalho possa ser aproveitado tanto no meio acadêmico quando por empresas de desenvolvimento de software interessados na evolução dos conceitos relacionados à Software como Serviço e no desenvolvimento de sistemas que sigam esse modelo. 


\section{Referências}

Antonelli, V. Brasil considerado um dos principais mercados para SaaS. In: Portal Call Center, 2008.

Disponível em http://www.portalcallcenter.com.br/gestao/crm/ brasil-considerado-um-dos-principais-mercados-para-saas

Arya, P. K.; Venkatesakumar, V.; Palaniswami, S. Configurability in SaaS for an electronic contract management application. In: Proceedings of the 12th international conference on Networking, VLSI and signal processing, 2010, p. 7.

Banerjee, P.; Friedrich, R.; Bash, C.; Goldsack, P.; Huberman, B. A.; Manley, J.; Patel, C.; Ranganathan, P.; Veitch, A. Everything as a Service: Powering the New Information Economy. v. 44, n. 3, p. 36-43, 2011.

Bezemer, C.-P.; Zaidman, A. Multi-tenant SaaS Applications: Maintenance Dream or Nightmare? In: Proceedings of the Joint ERCIM Workshop on Software Evolution (EVOL) and International Workshop on Principles of Software Evolution (IWPSE), IWPSE-EVOL '10, New York, NY, USA: ACM, 2010, p. 88-92 (IWPSE-EVOL '10, ). Disponível em http://doi.acm.org/10.1145/1862372.1862393

Boillat, T.; Legner, C. From on-premise software to cloud services: The impact of cloud computing on enterprise software vendors' business models. Journal of Theoretical and Applied Electronic Commerce Research, v. 8, n. 3, p. 39-58, 2013.

Disponível em http://dx.doi.org/10.4067/S0718-18762013000300004

Chae, J.; Yoo, C.; Kim, Y.; Chang, O. XSLT template design for generating the web presentation layer. In: Tenth Asia-Pacific Software Engineering Conference, 2003., Ieee, 2003, p. 396-404. 
Cherobino, V. SaaS: Quatro letras para conquistar as pequenas empresas. In: ComputerWorld, 2007.

Disponível em http://computerworld.uol.com.br/gestao/2007/10/16/ idgnoticia.2007-10-15.3940692242/

Elmore, A. J.; Das, S.; Pucher, A.; Agrawal, D.; El Abbadi, A.; Yan, X. Characterizing tenant behavior for placement and crisis mitigation in multitenant DBMSs. In: Proceedings of the 2013 ACM SIGMOD International Conference on Management of Data, SIGMOD '13, New York, NY, USA: ACM, 2013, p. 517-528 (SIGMOD '13, ).

Disponível em http://doi.acm.org/10.1145/2463676.2465308

Freeman, A. Pro ASP.NET MVC \& (Professional Apress). 4th ed. Berkely, CA, USA: Apress, 2013.

Ghaddar, A.; Tamzalit, D.; Assaf, A.; Bitar, A. Variability As a Service: Outsourcing Variability Management in Multi-tenant Saas Applications. In: Proceedings of the 24th International Conference on Advanced Information Systems Engineering, CAiSE'12, Berlin, Heidelberg: Springer-Verlag, 2012, p. 175-189 (CAiSE'12, ).

Disponível em http://dx.doi.org/10.1007/978-3-642-31095-9_12

Hudli, A. V.; Shivaradhya, B.; Hudli, R. V. Level-4 SaaS applications for healthcare industry. In: Proceedings of the 2nd Bangalore Annual Compute Conference, COMPUTE '09, New York, NY, USA: ACM, 2009, p. 19:1—-19:4 (COMPUTE '09, ).

Kabbedijk, J.; Jansen, S. The Role of Variability Patterns in Multi-tenant Business Software. In: Proceedings of the WICSA/ECSA 2012 Companion Volume, WICSA/ECSA '12, New York, NY, USA: ACM, 2012, p. 143-146 (WICSA/ECSA '12, ).

Disponível em http://doi.acm.org/10.1145/2361999.2362029

Kaplan, J. How SaaS is Overcoming Common Customer Objections. Cutter Consortium: Sourcing and Vendor Relationships, AdvisoZry Service, Executive Update, v. 8, n. 9, p. 1-6, 2008.

Kim, W.; Lee, J. H.; Hong, C.; Han, C.; Lee, H.; Jang, B. An Innovative Method for Data and Software Integration in SaaS. Computers and Mathematics with Applications, v. 64 , n. 5, p. 1252-1258, 2012.

Disponível em http://dx.doi.org/10.1016/j.camwa.2012.03.069

Kitano, T.; Iguchi, K.; Koyama, K. Generating Robust XPaths for Service Customization. 2010 6th World Congress on Services, , n. 1, p. 166-167, 2010. 
Krasner, G. E.; Pope, S. T. A Cookbook for Using the Model-view Controller User Interface Paradigm in Smalltalk-80. J. Object Oriented Program., v. 1, n. 3, p. 26-49, 1988.

Disponível em http://dl .acm.org/citation. cfm?id=50757.50759

Kumara, I.; Han, J.; Colman, A.; Nguyen, T.; Kapuruge, M. Sharing with a Difference: Realizing Service-Based SaaS Applications with Runtime Sharing and Variation in Dynamic Software Product Lines. In: Proceedings of the 2013 IEEE International Conference on Services Computing, SCC '13, Washington, DC, USA: IEEE Computer Society, 2013, p. 567-574 (SCC'13, ).

Disponível em http://dx.doi.org/10.1109/SCC.2013.30

Kwok, T.; Nguyen, T.; Lam, L. A software as a service with multi-tenancy support for an electronic contract management application. In: IEEE International Conference on Services Computing, 2008. SCC '08, 2008, p. 179 -186.

Lee, W.; Choi, M. A Multi-tenant Web Application Framework for SaaS. In: Proceedings of the 2012 IEEE Fifth International Conference on Cloud Computing, CLOUD '12, Washington, DC, USA: IEEE Computer Society, 2012, p. 970-971 (CLOUD '12, ).

Disponível em http://dx.doi.org/10.1109/CLOUD.2012.27

Li, D.; Zhang, W.; Zhou, S.; Liu, C.; Jin, W. Portal-based design for SaaS system presentation layer configurability. In: 6th International Conference on Computer Science Education (ICCSE), 2011, 2011, p. 1327-1330.

Liao, H.; Tao, C. An Anatomy to SaaS Business Mode Based on Internet. In: Pro. Intl. Conference on Management of e-Commerce and e-Government (ICMECG), 2008, p. $215-220$.

Disponível em http://dx.doi.org/10.1109/ICMECG.2008.16

Lisserman, M. SaaS And The Everlasting Security Concerns. 2010.

Disponível em http://community.forrester.com/message/10906

Liu, Z.; Hacumus, H.; Moon, H. J.; Chi, Y.; Hsiung, W.-P. PMAX: tenant placement in multitenant databases for profit maximization. In: Proceedings of the 16th International Conference on Extending Database Technology, EDBT '13, New York, NY, USA: ACM, 2013, p. 442-453 (EDBT' '13, ).

Disponível em http://doi.acm.org/10.1145/2452376.2452428

Maluf, D. A.; Okimura, T.; Gurram, M. NASA Technology Transfer System. In: Proceedings of the 2011 IEEE Fourth International Conference on Space Mission Challenges 
for Information Technology, SMC-IT '11, IEEE, 2011, p. 111-117 (SMC-IT '11, ). Disponível em http://dx.doi.org/10.1109/SMC-IT.2011.27

Manduca, A. M. Transforming a Web Application into a Multitenant SaaS (in Portuguese). Java Magazine, v. 120, 2013.

Manduca, A. M.; Munson, E. V.; Fortes, R. P. M.; Pimentel, M. G. C. A Nonintrusive Approach for Implementing Single Database, Multitenant Services from Web Applications. In: Proceedings of the 29th Annual ACM Symposium on Applied Computing, SAC '14, New York, NY, USA: ACM, 2014 (SAC '14, ).

Mäkilä, T.; Järvi, A.; Rönkkö, M.; Nissilä, J. How to define software-as-a-service - an empirical study of finnish saas providers. In: Tyrväinen, P.; Jansen, S.; Cusumano, M., eds. Software Business, v. 51 de Lecture Notes in Business Information Processing, Springer Berlin Heidelberg, p. 115-124, 2010.

Disponível em http://dx.doi.org/10.1007/978-3-642-13633-7_10

Nitu Configurability in SaaS (software as a service) applications. In: Proceedings of the 2nd India software engineering conference, ISEC '09, New York, NY, USA: ACM, 2009, p. 19-26 (ISEC' '09, ).

Piller, F.; Tseng, M. A Mass Of Customizers: The WordPress Software Ecosystem. In: Handbook of Research in Mass Customization and Personalization: Strategies and concepts, v. 2, World Scientific, 2010.

Rodrigues, J.; Leite, A.; Damasceno, J. C.; Garcia, V. C.; Silveira, P.; Meira, S. R. L. An Approach to Developing Multi-tenancy SaaS Using Metaprogramming. In: Proceedings of the 18th Brazilian Symposium on Multimedia and the Web, WebMedia '12, New York, NY, USA: ACM, 2012, p. 207-210 (WebMedia '12, ).

Disponível em http://doi.acm.org/10.1145/2382636.2382681

Rosenfield, C. Gartner Forecasts That The SaaS Market Will Grow To $\$ 32.8$ Billion In 2016. In: Qoints, 2013.

Disponível em http://qoints.com/2013/09/14/market-insight/ gartner-forecasts-that-the-saas-market-will-grow-to-32-8-billion-in-2016/

Schaffner, J.; Januschowski, T.; Kercher, M.; Kraska, T.; Plattner, H.; Franklin, M. J.; Jacobs, D. RTP: robust tenant placement for elastic in-memory database clusters. In: Proceedings of the 2013 ACM SIGMOD International Conference on Management of Data, SIGMOD '13, New York, NY, USA: ACM, 2013, p. 773-784 (SIGMOD '13, ). Disponível em http://doi.acm.org/10.1145/2463676.2465302 
Sengupta, B.; Roychoudhury, A. Engineering multi-tenant software-as-a-service systems. In: Proceedings of International Workshop on Principles of Engineering Service-Oriented Systems, PESOS '11, ACM, 2011, p. 15-21 (PESOS '11, ).

Disponível em http://doi.acm.org/10.1145/1985394.1985397

Sun, W.; Zhang, X.; Guo, C. J.; Sun, P.; Su, H. Software as a service: Configuration and customization perspectives. In: Congress on Services Part II, 2008. SERVICES-2. IEEE, 2008, p. $18-25$.

Wei, Z.; Ni, X.; Jia, D. Research on software reuse of user interface for mobile computing devices based on XML. In: Software Engineering and Service Sciences (ICSESS), 2010 IEEE International Conference on, n. 2008, IEEE, 2010, p. 146-149.

Weissman, C. D.; Bobrowski, S. The design of the force.com multitenant internet application development platform. In: Proceedings of the 35th SIGMOD international conference on Management of data, SIGMOD '09, New York, NY, USA: ACM, 2009, p. 889-896 (SIGMOD'09, ).

Wikipedia Software as a Service. 2012.

Disponível em http://en.wikipedia.org/wiki/Software_as_a_service

Yao, P.; Wen, H.-y.; Dai, Q.-j. Study on Presentation Layer Structure of Multi-tenant E-business Systems. Information Systems, p. 1-3, 2011.

Zainuddin, E.; Gonzalez, P. Configurability, Maturity, and Value Co-creation in SaaS: An Exploratory Case Study. In: ICIS 2011 Proceedings, 2011.

Zainuddin, E.; Staples, S. Enhancing SaaS with Insufficient Domain Knowledge. In: 16th UKAIS Conference Proceedings, 2011. 